NBER WORKING PAPER SERIES

\title{
RECIPROCATED UNILATERALISM IN TRADE POLICY: AN INTEREST-GROUP APPROACH
}

\author{
Pravin Krishna \\ Devashish Mitra \\ Working Paper 9631 \\ http://www.nber.org/papers/w9631 \\ NATIONAL BUREAU OF ECONOMIC RESEARCH \\ 1050 Massachusetts Avenue \\ Cambridge, MA 02138 \\ April 2003
}

For helpful discussions and comments we are very grateful to seminar and conference participants at Board of Governors of the Federal Reserve, Boston College, Brandeis University, University of British Columbia, Brown University, University of California at Irvine, Columbia University, University of Connecticut, Dartmouth, Florida International University, INSEAD, Korea Development Institute, New York University, University of Notre Dame, Syracuse University, Yale University, the NBER's 1999 Summer Institute in Cambridge, MA, the AEA's 2000 meetings in Boston, the Fall 1999 Mid-West International Economics Conference at the University of Illinois at Urbana-Champaign, the Fall 1999 Southeastern International Economics conference at Georgetown University and the Ford Foundation - American Enterprise Institute conference on "Unilateralism: The Case for Relaxed Reciprocity." Pravin Krishna gratefully acknowledges the hospitality and the intellectual and financial support of the Center for Research on Economic Development and Policy Reform at Stanford University and the Research Department of the International Monetary Fund, where some of this research was conducted. The views expressed herein are those of the authors and not necessarily those of the National Bureau of Economic Research.

(C2003 by Pravin Krishna and Devashish Mitra. All rights reserved. Short sections of text not to exceed two paragraphs, may be quoted without explicit permission provided that full credit including Cnotice, is given to the source. 
Reciprocated Unilateralism in Trade Policy: An Interest-Group Approach

Pravin Krishna and Devashish Mitra

NBER Working Paper No. 9631

April 2003

JEL No. F13, F10, F02

\section{ABSTRACT}

Using the menu-auction approach to endogenous determination of tariffs and allowing additionally for lobby formation itself to be endogenous, this paper analyzes the impact of unilateral trade liberalization by one country on its partner's trade policies. We find that such unilateral liberalization may induce reciprocal tariff reductions by the partner country. Intuitively, unilateral liberalization by one country has the effect of increasing the incentives for the export lobby in the partner country to form and to lobby effectively against the import-competing lobby there for lower protection.

Pravin Krishna

Department of Economics

Brown University

64 Waterman Street

Providence, RI 02912

and NBER

Pravin_Krishna@brown.edu
Devashish Mitra

Department of Economics

Maxwell School of Citizenship and Public Affairs

Syracuse University

133 Eggers Hall

Syracuse, NY 13244

and NBER

dmitra@maxwell.syr.edu 


\section{Reciprocated Unilateralism in Trade Policy: An Interest-Group Approach}

\section{Introduction}

In trade policy debates, the issue of unilateralism (i.e., the unilateral adoption of liberal trade policies) versus reciprocity (where reciprocity of access is insisted on instead) is a long standing one. ${ }^{1}$ The theoretical arguments used by proponents of either policy stance are well known: Unilateralists rely upon the demonstration that in the absence of "distortions," free trade is efficient, while a policy stance of reciprocity is theoretically supported by the presence of "terms-of-trade" and political economy motivations in the economy. ${ }^{2}$

In contrast to much of this literature, which has considered these two approaches to trade liberalization independently of each other, it is the goal of this paper to study the possible causal interaction between unilateral and reciprocal trade liberalization. Specifically, we are interested in examining the question of whether unilateral trade liberalization by one country could induce reciprocal liberalization by its partner in the absence of any communication or negotiation between these two countries. The theoretical platform that we use to investigate this point is the popular construct of Grossman and Helpman (1994), where tariffs are determined by the interaction between competing domestic lobbying groups and

\footnotetext{
${ }^{1}$ Thus, one may consider the recent policy debates in the United States or go back a hundred and fifty years and examine the policy discussions preceding England's famous unilateral repeal of its Corn Laws to find free traders and reciprotarians actively pitted against each other. For an excellent discussion of debates in nineteenth century England between "unilateralists" and "reciprotarians" and of parallels with late twentieth century US, see Bhagwati and Irwin (1987).

${ }^{2}$ Thus, for instance, Mayer (1981) showed that in the presence of terms of trade motivations for tariffs, international negotiations could lead to a better outcome than the non-cooperative Nash outcome derived earlier by Johnson (1956). Equally, political economy influences have been considered in models explaining agreed-upon reciprocal trade liberalization in the work of Mayer (1984a), Hillman and Moser (1996) and Bagwell and Staiger (1998), among others.
} 
the government, ${ }^{3}$ and where the government's objective function itself includes political contributions from organized lobbies and also aggregate welfare. An important feature of our analysis is that formation of organized lobbies itself is treated as being endogenous, as in Mitra (1999). ${ }^{4}$ In this context, it is this paper's central finding that unilateral tariff liberalization by one country, by altering the political economy equilibrium in the partner country, may indeed result in reciprocal tariff reduction by the partner. We believe that this result carries interesting normative implications: It stands in stark contrast to the conventional policy wisdom on this matter regarding the use of (the threat of) one's trade barriers to remove those of others - as exemplified by the United States' recent use of the "Super-301" provision to "retaliate" by raising trade barriers against countries whose trade barriers are perceived as unreasonable. ${ }^{5}$

The linkage between unilateralism and reciprocal liberalization that we have in mind is as follows: Consider a small open economy trading with a large partner. Further, to fix ideas, consider an initial situation in which the import-competing sector in the small country is

\footnotetext{
${ }^{3}$ Thus we take the "political-economy" approach, following the pioneering work of Stigler (1971), Peltzman (1976) and Becker (1983) in modeling "pressure-groups" in general and the work of Findlay and Wellisz (1982), Hillman (1982), Bhagwati and Feenstra (1982), Mayer (1984b), Hillman and Ursprung (1988), Magee, Brock and Young (1989) and Grossman and Helpman (1994), in considering explicitly political-economy considerations (often the impact of lobbies) in determining trade policy outcomes. Recent work in this area includes Helpman and Persson (1998), which looks at the interaction between lobbying and legislative bargaining and the implications of such an interaction for the determination of economic policy, Grossman and Helpman (1995a and 1995b) and Maggi and Rodriguez-Clare (1998). Helpman (1995) and Rodrik (1995) both provide excellent surveys of recent developments.

${ }^{4}$ While we make substantial use of the theoretical structures of both these papers to make our point, it should be clear that our work differs significantly in motivation and spirit from both these earlier papers, neither of which is concerned with the central issue that motivates the present analysis - the possible causal connection between unilateral liberalization and its reciprocation by a partner country and the normative implications of this interaction.

${ }^{5}$ Our results should not be read as saying, however, that there isn't value to negotiation or the requirement of reciprocity in trade negotiations. We are simply suggesting that taking a more sophisticated view of the underlying politics in one's trading partners suggests a stronger role for unilateralism than previously emphasized in the theoretical literature. On the merits of reciprocity rules, see, for instance, the recent and important paper by Bagwell and Staiger (1998).
} 
represented by an organized lobby but the exportables sector is not (due to a fixed cost requirement faced by this sector which in this initial equilibrium exceeds the benefits it could get from the formation of the lobby). Consequently, its (Grossman-Helpman) trade policy vector (determined by lobbying by the import-competing lobby and the government preferences) is characterized by import tariffs (which raise the lobby's profits) and export taxes (which lower the lobby's cost of consuming the exportable good). ${ }^{6}$ In this context, unilateral liberalization by the large partner country can be shown to generally increase the incentives for the formation of an export lobby in the small country. This happens for two reasons: First, a higher world price of the exportable good (resulting from this liberalization) makes the existing trade policy vector more costly for the export lobby. Secondly, at higher export prices (in the absence of an export lobby) the import-competing lobby has incentives to lobby for a trade policy vector even more biased against the exporting lobby - further raising the incentives for formation of the export lobby. Once formed, this export lobby then competes effectively with the import-competing lobby to oppose the orientation of existing trade policies (i.e., to reduce domestic tariffs and export taxes). Unilateral liberalization by one country therefore has a "strategic" effect on the relevant groups in the partner country so that freer trade is the outcome. ${ }^{7}$

Several additional points relating to the empirical validity of our results and their connection with the rest of the theoretical literature may be made here:

\footnotetext{
${ }^{6}$ The export tax derived in the Grossman-Helpman model should not be taken literally. As is well known, in multi-sector general equilibrium models with perfect competition, the imposition of import taxes on all imports is itself equivalent to export taxes being imposed on all exports at the same ad valorem rate (Lerner symmetry). Further, if intermediates are used in production (specifically if the importable is used in the production of the exportable good), it should be clear to see that the import tax itself acts as a tax on the exportable sector.

${ }^{7}$ This causal link is similar to the one suggested informally by Bhagwati (1990) that "concessions to the foreign exporters," through a reduction in home country tariffs, "may create new interests that counterbalance the interests that oppose trade liberalization" there. See also the related and important work of McLaren $(1997,1999)$, which variously analyzes the implications of fixed and sunk investment by forwardlooking firms on the trade policy choices of domestic and foreign governments.
} 
First, we should note that the type of result demonstrated in the paper is indeed possible in the classic Johnson (1956) analysis of optimal tariffs if the tariff reaction functions there are upward sloping. There too, a unilateral tariff reduction by one country would result in tariff reductions by the partner (again, if the partner's tariff reaction function is upward sloping). However, it should be clear that our analysis differs in significant theoretical (and finally empirically relevant) ways from the Johnsonian analysis. In our framework, a unilateral liberalization by a country would affect even a "small" country's trade policies, whereas in the Johnsonian analysis, a small open economy keeps its tariffs fixed at zero independently of the tariffs imposed by the large partner country. Thus, in our framework, unilateralism may be reciprocated even in the absence of terms of trade motivations for the partner - an outcome that is not possible in the Johnsonian framework. Furthermore, in Johnson's analysis, upward sloping reaction functions can only be derived if partner export supply elasticities are falling in partner country tariffs. Our results do not depend upon this monotonic elasticity relationship (whose empirical validity itself may be questioned - indeed most textbook treatments normally consider the opposite case - that of downward sloping reaction functions - while admitting the theoretical possibility of upward slopes). In any event, these are not mutually exclusive theories. Johnson's upward sloping reaction functions (even if empirically valid) do not interfere with the mechanisms suggested in this paper. Which theory is of greater relevance is an empirical question whose detailed consideration is outside of the scope of this paper.

Second, without making a strong empirical claim, we should note that the prediction of our model is consistent with a few major episodes of unilateral trade liberalization which are well known in the history of international economic relations. ${ }^{8}$ As Coates and Ludema (1997)

\footnotetext{
${ }^{8}$ Separately, the role of sunk costs in political organization and the endogenous formation of lobbies in response to improved economic incentives to do so has been analyzed recently in the empirical investigation of the 1945 Reciprocal Trade Agreements Act (RTAA) by Irwin and Kroszner (1997).
} 
argue, these include the unilateral repeal of England's Corn Laws in the mid-nineteenth century, "after decades of attempts to negotiate lower tariffs with its trading partners" and the more recent example of the United States, which, after the end of the Second World War sponsored the General Agreement on Trade and Tariffs (GATT) and engaged subsequently in major tariff reductions "without requiring substantive reciprocity from its major trading partners." "Waves of liberalization" by trading partners followed both these episodes. In the period immediately after England's repeal of its Corn laws, numerous countries followed suit - with unilateral trade reforms of their own or with bilateral tariff agreements with England. Equally, the major trading partners of the United States reduced their trade barriers in the subsequent period leading upto the 1970s. ${ }^{9}$ In this context, the recent experiences of many developing countries also seem relevant. Following trade barrier reductions by fullobligation (i.e., developed country) GATT members in the several GATT rounds, there have been dramatic reductions of trade barriers by many developing countries which were exempt from the obligation to reciprocate by the articles (specifically, Article XVIII) of the GATT. ${ }^{10}$ This is roughly consistent with the theoretical predictions of the model: Unilateralism may be reciprocated even in the absence of a formal obligation to do so.

We should note also the similarity in motivation of our work with that of Coates and Ludema (1997), who study the impact of unilateral tariff reduction on negotiation outcomes (specifically the likelihood of success of achieving bilateral agreements in the presence of the "political risk" of domestic opposition to trade agreements) and argue that unilateral trade

\footnotetext{
${ }^{9}$ It is not our intention here to dispute any other explanations provided by the economic history literature on this matter. Having pointed to a particular channel which we believe to be theoretically interesting and empirically plausible, we leave its empirical validity in particular historical contexts as a topic for future research. See Coates and Ludema $(1997)$ and Kindleberger $(1975,1977)$ for excellent discussions of the explanations provided by economic historians on this issue.

${ }^{10}$ We should note here that the relevance of interest groups in trade policy determination in developing countries, as assumed in the theoretical framework we use in this paper, has been established in a number of recent empirical papers, including deMelo, Grether and Olarreaga (2001) and Mitra, Thomakos and Ulubasoglu (2002).
} 
liberalization may be the optimal policy for a large country. In their framework, "unilateral liberalization acts as insurance" by providing a "risk-sharing" role. Unilateral tariff reduction lowers the political stakes associated with trade liberalization in the foreign country, thereby lowering the overall political cost of reaching and implementing trade agreements and increasing the probability of successful agreements.

To sum up, we believe the contribution of the paper to be three-fold: It is among the first formal analyses of the interaction between unilateralism and reciprocal liberalization that we are aware of. Second, in studying this interaction it articulates channels through which unilateralism could lead to the organization of export interests in partner countries and thus induce reciprocity - a result which we believe holds interesting normative implications. Finally, in serving as a potential explanation for some well-known historical episodes of trade reform that we have mentioned, we believe that our paper has some positive significance as well.

Before proceeding with the formal model, we should note a point regarding the modeling strategy here: While we treat explicitly the formation of lobbies and tariffs in the "small" economy, the tariff reduction in the large economy is modeled as being exogenous (i.e., the level of the tariff imposed by the large open economy is taken as given by agents in the small country). This is done for analytical convenience since it appears to us to be the simplest framework within which to communicate the central idea of the paper - i.e., that there exist channels through which tariff reductions in one country (however they come about) could lead to reciprocal tariff reductions by its partners. However, even taking this assumption of "exogenous tariff reduction" literally, several examples may be offered in justification: Thus, for example, the model may be interpreted as representing a situation in which developed country GATT members negotiate tariff reductions amongst themselves and bind their tariffs at the end of such negotiations. Developing country members are beneficiaries of these tariff 
reductions due to the most-favored-nation (MFN) principle of the GATT, but may not be under full obligation to reciprocate (due to Article XVIII of the GATT). The possible reciprocity (in the form of tariff reductions by the developing countries, for instance) that may nonetheless be induced by such tariff reductions by developed countries is what this model studies. An alternate interpretation is to think of the model as studying the effects on partner countries of tariff reductions that may occur in certain countries due to regime shifts involving ideological changes (the ascension of committed free-traders into political power, for instance). A third interpretation is to think of the model as studying the impact of trade policy changes undertaken by some countries due to conditionality imposed on them by international bodies such as the International Monetary Fund as part of a larger scheme to restructure the economy. In each of these cases, one may argue that agents in the partner countries (i.e., lobbies) take the tariff changes as being given rather than being endogenous to their own actions.

The rest of the paper proceeds as follows: Section II outlines the basic model describing endowments, technology and preferences in a small economy that is involved in trade with a "large" partner. Section III discusses the endogenous formation of lobbies and trade policy in the small country and derives the initial equilibrium. Section IV demonstrates the scope for reciprocal liberalization by the small country when tariffs are liberalized by its large partner. To examine the welfare impact on the large unilaterally liberalizing country, Section V extends the analysis to the case where the large country trades with a large number of small open economies. Section VI derives optimal tariffs - both when the large country takes the structure of lobbies in these small economies as being fixed and when alternately it takes into account the impact that it may have in influencing the structure of lobbies and consequently trade policy in its partner countries. Section VII describes the results of simulation analysis conducted with a view to exploring the implications of our framework under circumstances (i.e., initial conditions) other than those we focus on in the main section 
of the paper. Section VIII concludes.

\section{The Model}

Consider a small open economy producing a numeraire good $z$ with Ricardian technology and two non-numeraire goods (an import-competing and an exportable good), $x_{m}$ and $x_{e},{ }^{11}$ each requiring a different kind of factor of production specific to that good and labor for their production. Individuals in this economy are assumed to have identical preferences with their utility functions taking the following form:

$$
U=c_{z}+\sum_{i} u_{i}\left(c_{x_{i}}\right), \quad i=m, e,
$$

where $c_{z}$ is consumption of the numeraire good, $c_{x_{i}}$ is consumption of good $x_{i}$ and $u_{i}\left(c_{x_{i}}\right)$ denotes the sub-utility derived from the consumption of the $i^{\text {th }}$ non numeraire good $\left(u^{\prime}>0\right.$ and $\left.u^{\prime \prime}<0\right)$. Consumers then solve the following optimization problem:

$$
\max _{c_{z}, c_{x_{i}}} U=c_{z}+\sum_{i} u_{i}\left(c_{x_{i}}\right) \text { subject to } \sum_{i} p_{i} c_{x_{i}}+c_{z}=E
$$

where $E$ is total income and where $p_{m}$ and $p_{e}$ denote the domestic prices of these two goods (the world price of goods $x_{i}$ is assumed to be exogenously given at $p_{i}^{*}$ ).

From the first-order conditions, we have demand for the non-numeraire goods given by:

$$
c_{x_{i}}=d_{i}\left(p_{i}\right)
$$

where $d($.$) is the inverse of u^{\prime}($.$) .$

\footnotetext{
${ }^{11} \mathrm{As}$ is standard in the literature, it is assumed that this numeraire good is freely traded between countries - indeed it is exchanges of this numeraire good that serve to settle the balance of trade. Thus, this good may be imported or exported by any country based on its balance of trade in the remaining goods. Regardless, we shall refer to this good as simply the "numeraire" good and use the terms importable good and exportable good to refer exclusively to the goods $x_{m}$ and $x_{e}$ respectively.
} 
The demand for the numeraire good, in turn, is given by

$$
c_{z}=E-\sum_{i} p_{i} d_{i}\left(p_{i}\right)
$$

Given our assumption regarding the form of the utility function, the indirect utility function is given by

$$
\nu(\mathbf{p}, E)=E+\sigma(\mathbf{p})
$$

where $\mathbf{p}=\left(p_{m}, p_{e}\right)$ is the vector of domestic prices of the non-numeraire goods and

$$
\sigma(\mathbf{p})=\sum_{i} u_{i}\left(d_{i}\left(p_{i}\right)\right)-\sum_{i} p_{i} d_{i}\left(p_{i}\right)
$$

is consumer surplus.

As stated earlier, good $z$ is manufactured using labor alone under constant returns to scale (CRS). We set the input-output coefficient equal to one by choice of units (i.e., $z=L_{z}$ ), so that the wage rate $w=1$ in a competitive equilibrium. The output of each non-numeraire good is given by the following production function

$$
x_{i}=F_{i}\left(K_{i}, L_{i}\right)
$$

where $K_{i}$ is the sector specific factor used in the production of the $i^{\text {th }}$ good and $L_{i}$ is the amount of labor used in the $i^{\text {th }}$ good. $F_{i}($.$) is assumed to be CRS and subject to$ diminishing returns to each factor.

The quantity of each non-numeraire good supplied domestically is then given by:

$$
x_{i}=x_{i}\left(p_{i}\right)=\pi_{i}^{\prime}\left(p_{i}\right)
$$

where $\pi_{i}\left(p_{i}\right)$ is the profit function and gives the total reward to $K_{i}{ }^{12}$

\footnotetext{
${ }^{12}$ It can easily be shown that $\pi_{i}^{\prime \prime}\left(p_{i}\right)>0$, i.e., the profit function is convex with respect to price - a property that we will use later in deriving our results.
} 
Individual income in this economy is augmented by lump-sum (and uniform) redistribution of income derived from trade taxes and subsidies. ${ }^{13}$ The net revenue from taxes and subsidies, expressed on a per capita basis is given by

$$
\tau(\mathbf{p})=\sum_{i}\left(p_{i}-p_{i}^{*}\right)\left[d_{i}\left(p_{i}\right)-(1 / N) x_{i}\left(p_{i}\right)\right]
$$

where $N$ is the total population and $p_{i}^{*}$ denotes the world price of good $i$.

Thus, if $l^{h}$ represents individual $h$ 's endowment of labor and if $s_{i}^{h}$ denotes its share of the $i^{\text {th }}$ specific factor, the income of this individual is then given by

$$
E^{h}=l^{h}+\sum_{i} s_{i}^{h} \pi_{i}\left(p_{i}\right)+\tau(\mathbf{p}) \quad h=1,2 \ldots N .
$$

Finally, the indirect utility function of individual $h$ is given by

$$
\nu^{h}(\mathbf{p})=l^{h}+\sum_{i} s_{i}^{h} \pi_{i}\left(p_{i}\right)+\tau(\mathbf{p})+\sigma(\mathbf{p})
$$

To get to endogenous determination of tariffs and lobbies, we make some simplifying assumptions regarding the structure of endowments and ownership of specific factors in this economy. First, we assume that each individual in the economy is endowed with exactly $l$ units of labor. Further, we assume that each individual owns only one type of specific factor and that owners of any particular type of specific factor are symmetric (that is, they own identical amounts of that specific factor). Letting $\theta$ denote the fraction of the population that owns the kind of specific factor used in the production of the importable and $1-\theta$ denote the proportion of population that owns the other specific factor, ${ }^{14}$ we have the total

\footnotetext{
${ }^{13}$ Following Grossman and Helpman (1994), we assume that the only policy instruments available to politicians are trade taxes and subsidies. For some interesting implications of the presence of other policy instruments such as consumption and production taxes and subsidies at the disposal of the government in the presence of exogenously determined lobbies, see Dixit (1996).

${ }^{14}$ Thus, we assume that the entire population owns some specific factor. As will quickly become evident,
} 
gross welfare of the set of individuals owning the $i^{\text {th }}$ specific factor to be given by

$$
\Omega^{i}(\mathbf{p})=\alpha_{i} N l+\pi_{i}\left(p_{i}\right)+\alpha_{i} N[\tau(\mathbf{p})+\sigma(\mathbf{p})]
$$

where

$$
\alpha_{i}=\left\{\begin{array}{l}
\theta \text { when } i=m \\
1-\theta \text { when } i=e
\end{array}\right.
$$

\section{Determination of the Structure of Lobbies and Protection}

As in Grossman and Helpman (1994), the government is assumed to care about the total level of political contributions that it may receive and about aggregate well-being. The government values contributions because they can be used to finance campaign spending or provide other direct benefits to office holders. Social welfare is of concern to the government since voters would more likely re-elect a government that has delivered a high standard of living. A linear objective function is assumed to represent these preferences:

$$
\Omega^{G}(\mathbf{p})=\left[\sum_{i \in \Lambda} C_{i}(\mathbf{p})+a \Omega^{A}(\mathbf{p})\right]
$$

where $\Lambda$ is the set of organized interest groups (lobbies), $\Omega^{G}(\mathbf{p})$ is the objective function of the government, $\Omega^{A}(\mathbf{p})$, is aggregate gross social welfare, ${ }^{15} C_{i}(\mathbf{p})$ is the contribution schedule of the $i^{\text {th }}$ lobby and $a$ is the weight the government attaches to aggregate social

this delivers strong results with changing lobby structure. However, we should note that the qualitative spirit of our results is preserved even with greater concentration of ownership of specific factors, i.e., if $\alpha_{e}+\alpha_{m}<1$. Further, even at very high levels of concentration of ownership of factors, i.e., with $\alpha_{e}+\alpha_{m}$ approaching zero, the qualitative spirit of our results is maintained if we include and consider other features such as intermediate inputs which are importables or the potential formation of consumer lobbies. Including either of these in the model would restore the general equilibrium linkages that break down with very high concentration of factor ownership and preserve the spirit of our results.

\footnotetext{
${ }^{15}$ Since this paper is eventually concerned with causes and consequences of lobby formation, we shall shortly introduce additional notation in the form of subscripts attached to $\Omega$ that denote which lobbies are operational at any given time.
} 
welfare relative to political contributions. Clearly, the higher is $a$, the higher its concern for social welfare relative to its affinity for political contributions.

We are interested in the political equilibrium of the following three-stage non-cooperative game. In the first stage, specific factor owners in a sector decide whether to contribute to the financing of the fixed and sunk costs (defined in labor terms) of forming an organized lobby. This fixed cost consists of the costs of forming an organization, establishing links with politicians, hiring professional lobbyists, building a communications network among members, designing a scheme of punishments for defaulting members, etc. Forming a lobby can also be one way of getting closer to the government, so that political influence can be exercised on government's decision making. A lobby can be considered to be an organizational set up to reduce transactions costs in lobbying activity, coordinate campaign contributions and communicate political "offers" to the politicians. In sectors without lobbies, the individual owners consider themselves too small to communicate their offers or persuade the government to formulate economic policy one way or the other, since the transactions costs for these to be done at the level of the individual may be very high.

In the second stage, lobbies choose their political contribution schedules. As in Grossman and Helpman (1994), it is assumed that each organized industry provides the government with a contribution schedule that truthfully reveals its preferences taking into account the government's objective function. Finally, in the third stage, the government sets trade policy to maximize a weighted sum of political contributions and overall social welfare.

The problem is solved by working backwards, i.e., by starting from the third stage. Here, the government, facing the contribution schedules of organized lobbies, solves the following problem: 


$$
\max _{\mathbf{p} \in P} \Omega^{G}(\mathbf{p})=\left[\sum_{i \in \Lambda} C_{i}(\mathbf{p})+a \Omega^{A}(\mathbf{p})\right]
$$

where $P$ is the set of domestic price vectors from which the government may choose. As already noted, attention in this paper is restricted to equilibria that lie in the interior of $P$.

In the prior stage, lobbies are assumed to choose truthful contribution schedules. The schedule for each lobby $i \in \Lambda$ is given by

$$
C_{i}(\mathbf{p})=\max \left(0, \Omega_{i}(\mathbf{p})-b_{i}\right)
$$

where the scalars $b_{i}$ 's (the net welfare anchors for the different lobby groups) are determined in equilibrium. As in Grossman and Helpman, we focus on equilibria where lobbies make positive contributions. In other words, in the neighborhood of the equilibrium,

$$
C_{i}(\mathbf{p})=\Omega^{i}(\mathbf{p})-b_{i} .
$$

Substituting (12) into (11), we have,

$$
\max _{\mathbf{p} \in P} \Omega^{G}(\mathbf{p})=\left[\sum_{i \in \Lambda}\left(\Omega^{i}(\mathbf{p})-b_{i}\right)+a \Omega^{A}(\mathbf{p})\right] \quad \Rightarrow \max _{\mathbf{p} \in P}\left[\sum_{i \in \Lambda} \Omega^{i}(\mathbf{p})+a \Omega^{A}(\mathbf{p})\right]
$$

The solution to this maximization problem yields (Grossman and Helpman (1994)) the following expressions for trade taxes and subsidies, $t_{i}:{ }^{16}$

$$
\frac{t_{i}}{1+t_{i}}=\frac{I_{i}-\gamma}{a+\gamma} \cdot \frac{1}{\mu_{i} \epsilon_{i}}
$$

where $\gamma$ is the proportion of the population that belongs to any organized lobby in equilibrium, $\mu_{i}$ and $\epsilon_{i}$ denote the ratio of imports to domestic production and the absolute

${ }^{16}$ The expressions simply represent the Grossman-Helpman (1994) “modified Ramsey rule." 
value of the price elasticity of import demand respectively, if $i=m$, and denote the ratio of exports to domestic production of the exportable and the absolute value of the elasticity of export supply if $i=e$ instead. $I_{i}$ is an indicator variable which takes a value of one if the $i^{\text {th }}$ sector is organized and zero otherwise.

The immediate implication of (14) is that if both the exporting and importing sector in our framework are organized, we have free trade - since $\gamma=1$ and $I_{i}$ takes on the value of one for both sectors. This can be seen intuitively from (13). We know that when both lobbies are formed, the government is simply maximizing the weighted sum of overall welfare on the one hand and the sum of the surplus that accrues to each group on the other. This is simply a multiple of overall welfare anyway - which is maximized with free trade.

We are interested in understanding what the implications are of a reduction in tariffs by a large partner country on the equilibrium structure of tariff protection in this country. In this context, an initial equilibrium in which the small country is already at free trade is uninteresting. Thus, to begin with, we assume that at least one sector is organized. Without loss of generality, let us assume that only the import-competing sector is organized to begin with. ${ }^{17}$ Equation (14) gives us then that the trade regime is one that favors the import competing sector and in which the exporting sector is effectively taxed. The import tariff, $t_{m}$, and the export tax, $t_{e}$, are given respectively by:

$$
\frac{t_{m}}{1+t_{m}}=\frac{1-\theta}{a+\theta} \cdot \frac{1}{\mu_{m} \epsilon_{m}}
$$

\footnotetext{
${ }^{17}$ As we discuss in the next section, the spirit of our theoretical results is unaffected if we start instead with only the exporting lobby being organized. However, as Rodrik (1995) notes, it is a stylized fact that the vast majority of trade regimes that were liberalized in the recent years started with regimes in which the import competing sector enjoyed significant protection. Thus, we present our analysis under the maintained assumption that it is the import-competing sector that is organized initially.
} 


$$
\frac{t_{e}}{1+t_{e}}=\frac{-\theta}{a+\theta} \cdot \frac{1}{\mu_{e} \epsilon_{e}}
$$

Note that here, the tariff on imports, $t_{m}$, is positive and the protection to the export sector, $t_{e}$, is a negative number - indicating that it is a tax. In both cases, $\left(1+t_{i}\right)$ denotes the ratio $\frac{p_{i}}{p_{i}^{*}} \cdot 18$

We now go back to the first stage and analyze conditions under which we may have lobby formation (of the export lobby) itself, taking the import sector as organized. ${ }^{19}$ To save on notation, for the present analysis, we set (without any loss of generality) the world price of the importable good to be one. ${ }^{20}$ We also let $p_{e}^{*}=p^{*}$. Thus, $p^{*}$ now denotes the world relative price of the exportable. In this context, members of the exportable group decide whether to form a lobby or remain unorganized. To form the lobby, they face a fixed labor cost denoted by $F$. Nash interaction among group members is assumed in their contribution decisions towards the provision of the fixed labor cost of lobby formation. However, once the lobby is formed, it is assumed here that the lobby machinery can enforce perfect coordination among the members of that group in the collection of political contributions, i.e., given the symmetry of capital ownership by members within a group, the lobby machinery can enforce collection of equal amounts of political contributions from each capitalist in the sector. To compare the costs and benefits of lobby formation, we set up some additional notation as

\footnotetext{
${ }^{18}$ Henceforth when we talk of a higher tax, we mean a higher absolute value.

${ }^{19}$ Again, it is straightforward to do a similar analysis of the incentives for the import- competing sector to organize taking the export sector as organized. This is discussed in greater detail at the end of Section IV, where we discuss the implications of a unilateral liberalization by the partner on the net benefit from organizing for any group, taking the other group as organized.

${ }^{20}$ This is, of course, consistent with the small country assumption made here. In section $\mathrm{V}$, where we consider a large country and a large number of small open economies instead, we allow the world price of the importable good to vary.
} 
promised: Using “ ” to denote equilibrium values, we let $\tilde{\Omega}_{i, j}^{k}$ denote equilibrium gross welfare of the $k^{\text {th }}$ sector with both lobbies in place, $\tilde{\Omega}_{i}^{k}$ denote its equilibrium gross welfare with only the $i^{\text {th }}$ lobby in place and $\tilde{\Omega}^{k}$ denote its equilibrium gross welfare with no lobbies in place. Finally, we let $\tilde{C}$ denote the export lobby's equilibrium political contribution.

Now, depending upon the magnitude of the fixed costs relative to the benefits of lobby formation, there are three possibilities:

1. The benefit to any one individual within the exportable lobby exceeds the cost of forming the lobby. Here, contributing to the full financing of the fixed cost $F$ is the only Nash equilibrium outcome among the group members, i.e., a lobby is always formed when,

$$
\left(\tilde{\Omega}_{m, e}^{e}-\tilde{\Omega}_{m}^{e}-\tilde{C}\right) /(1-\theta) N>F
$$

2. Alternately, the cost of lobby formation exceeds the benefit to any one individual but is less than the total benefit to the lobby, i.e.,

$$
\tilde{\Omega}_{m, e}^{e}-\tilde{\Omega}_{m}^{e}-\tilde{C}>F>\left(\tilde{\Omega}_{m, e}^{e}-\tilde{\Omega}_{m}^{e}-\tilde{C}\right) /(1-\theta) N
$$

In this situation, there are two possible Nash equilibrium outcomes - either there is no contribution to the provision of the lobby or the fixed cost is fully financed. We assume that pre-play communication can take place. For example, when capitalists in an industry feel that they are going to benefit from forming a lobby, they start communicating with each other - write letters, make phone calls, etc. Hence, one can use some popular communication based refinements here. The better equilibrium for the group (i.e., the lobby is formed) satisfies the conditions for the three popular communication based refinements - coalition proof Nash, strong Nash and the Pareto-dominance refinement, and hence, group coordination becomes the likely equilibrium outcome. ${ }^{21}$

${ }^{21}$ Bernheim, Peleg and Whinston (1987) look at an important class of "non-cooperative" environments 
3. The cost of forming the lobby exceeds the benefit of lobby formation to the group, i.e.,

$$
\tilde{\Omega}_{m, e}^{e}-\tilde{\Omega}_{m}^{e}-\tilde{C}<F .
$$

The Nash equilibrium outcome is obviously "not providing the lobby" since the total benefit is less than the total fixed costs. From the analysis of the above three cases, the conclusion that emerges is that a lobby is formed under the following condition:

$$
\tilde{\Omega}_{m, e}^{e}-\tilde{\Omega}_{m}^{e}-\tilde{C}>F .
$$

Having described the initial equilibrium that we focus on and having derived conditions under which an (initially non-existent) export lobby may be formed, we proceed to analyze the impact of unilateral trade reform on this initial equilibrium.

\section{Unilateral Tariff Liberalization, Terms of Trade Changes and Endogenous Lobby Formation}

We are interested in how a unilateral tariff reduction by a large partner country (leading to an improvement in the export price $p^{*}$ faced by the "small" home country) may affect the initial equilibrium. In particular we are interested in how this may affect the equilibrium structure of lobbies and finally the equilibrium structure of tariffs.

where players can freely discuss their strategies, but cannot make binding commitments. They introduce a refinement of the Nash set, the concept of Coalition-Proof Nash equilibrium. An agreement is coalition-proof if and only if it is Pareto efficient within the class of self-enforcing agreements. In turn, an agreement is self-enforcing if and only if no proper subset (coalition) of players, taking the actions of its complement as fixed, can agree to deviate in a way that makes all its members better off. A more demanding refinement is the strong Nash refinement [Aumann (1959)] which requires that no coalition (including the whole set), taking the actions of its complement as given, can cooperatively deviate in a way that benefits all of its members. The Pareto dominance refinement requires that the Nash equilibrium is Pareto efficient among all possible Nash equilibria. 
To get to this, however, we need to develop a little additional notation. Thus, we let NB represent net benefit from lobby formation for the exportable sector. NB is net of political contributions, but gross of fixed costs. This net benefit is therefore given by

$$
\mathrm{NB}=\tilde{\Omega}_{m, e}^{e}-\tilde{\Omega}_{m}^{e}-\tilde{C}
$$

With truthful contributions, as in Grossman and Helpman (1994), the equilibrium contribution level by the exportable sector when organized is given by

$$
\tilde{C}\left(p^{*}\right)=\tilde{\Omega}_{m, e}^{e}-\tilde{b_{e}}\left(p^{*}\right)
$$

where $\tilde{b}_{e}$ is the net (of contributions) welfare or payoff anchor (determined in equilibrium) of the contribution schedule of the exportable group when organized. Note that this is different from the net benefit (gross of fixed costs) from lobby formation, NB, which is the difference between the net payoff $\tilde{b}_{e}=\tilde{\Omega}_{m, e}^{e}-\tilde{C}$ received as an organized group and the net payoff $\tilde{\Omega}_{m}^{e}$ as an unorganized group. Note also that the endogeneity of trade taxes and subsidies and thus domestic prices implies that equilibrium values of group welfare and contributions can now be written as functions of only the world price of the exportable, rather than as functions of domestic prices and trade taxes.

Importantly, with truthful contributions, any lobby when formed will have to pay the government an amount that makes it indifferent between treating that lobby as organized and treating it as unorganized, given the contribution schedule of the other lobbies. ${ }^{22}$ Thus, from (14), we know that the export lobby should compensate the government for the reduction in the import lobby's welfare due to its entry and for changes in overall social welfare. Therefore, the contribution of the export lobby is given by:

$$
\tilde{C}=\tilde{\Omega}_{m}^{m}-\tilde{\Omega}_{m, e}^{m}+a\left(\tilde{\Omega}_{m}^{A}-\tilde{\Omega}_{m, e}^{A}\right)
$$

\footnotetext{
${ }^{22}$ This is analogous to the celebrated Clark-Groves mechanism. See Bernheim and Whinston (1986) for a discussion.
} 
where the superscript " $A$ " stands for aggregate as before. We can now state our first proposition:

\section{Proposition 1:}

With a pre-existing import-competing lobby, the net benefit to the exporting sector from the formation of an export lobby (gross of fixed costs) is proportional to the sum of the deadweight losses created (relative to the free trade level) in the importable and the exportable sectors by the equilibrium trade policies that result when only the import-competing sector is organized.

This is seen by substituting (19) into (17). The net benefit to the export lobby from lobby formation can then be written as:

$$
\mathbf{N B}=\tilde{\Omega}_{m, e}^{e}-\tilde{\Omega}_{m}^{e}-\left[\left(\tilde{\Omega}_{m}^{m}-\tilde{\Omega}_{m, e}^{m}\right)+a\left(\tilde{\Omega}_{m}^{A}-\tilde{\Omega}_{m, e}^{A}\right)\right]=(a+1)\left(\tilde{\Omega}_{m, e}^{A}-\tilde{\Omega}_{m}^{A}\right)
$$

where the second equality derives from our assumption that all members of society own at least one specific factor. (20) tells us that the net benefit from lobby formation can simply be expressed in terms of the change in aggregate welfare due to the formation of the lobby. Since our utility functions are quasi-linear, aggregate change in welfare can simply be expressed in terms of surplus changes. The above expression for net benefit can then be usefully modified as follows:

$$
\mathbf{N B}=(a+1)\left(\Delta_{m}+\Delta_{e}\right)
$$

where $\Delta_{m}$ and $\Delta_{e}$ are the dead weight losses created in the importable and exportable sector respectively when only the importable sector is organized relative to when both lobbies are organized (i.e., the free trade level). This proves our proposition.

Our assumption regarding the initial equilibrium is equivalent to assuming that at the initial

level of world prices, $\mathbf{N B}<F$, that is, that the net benefit from lobby formation is less than 
the fixed cost of lobby formation and so the lobby does not form. The particular exercise that we wish to undertake relates to the effects of unilateral liberalization by a large partner country. As such, this would raise the world price of the small country's exportable good. To see how this may affect the incentives for lobby formation, we take the derivative of the above expression with respect to $p^{*}$. Then, under the additional sufficient assumption (which we discuss shortly) that $E_{s}(.)^{\prime \prime} \geq 0$ where $E_{s}$ is export supply from the small country, we have our second proposition:

\section{Proposition 2}

The net benefit from lobby formation to the exporting sector, NB, is increasing in the world price of the exportable, $p^{*}$.

Noting that the deadweight loss in the import competing sector, $\Delta_{m}$, does not depend upon $p^{*}$, and noting that the deadweight loss in the other sector can simply be expressed as a function of the world price of the exportable and the absolute value of the per unit tax on the exportable, $T=\left|p^{*} t_{e}\right|$, we have;

$$
\frac{d \mathbf{N B}}{d p^{*}}=(a+1) \frac{d \Delta_{e}}{d p^{*}}=(a+1)(\underbrace{\frac{\partial \Delta_{e}}{\partial T}}_{>0} \cdot \underbrace{\frac{d T}{d p^{*}}}_{>0}+\underbrace{\frac{\partial \Delta_{e}}{\partial p^{*}}}_{>0})>0
$$

(22) has three components on the right hand side which need to be signed:

The first component is the change in the dead weight loss in the exportable sector due to an increase in the absolute value of the tax. It is straightforward to see that this is positive.

The second component is the change in the absolute value of the export tax for a given change in international export prices. This is positive as well. While we save a formal proof 
for the Appendix A.1. we can state the intuition here: The reason that $T$ is increasing in $p^{*}$ is that at a high world price for the exportable, the gain to the organized group from a given reduction in the price of the exportable good is higher. This leads to more vigorous lobbying by the importable sector for a higher per-unit export tax (since they are consumers of this good). In turn, this leads to a higher per-unit export tax. This can be seen clearly in Figure I which represents changes in surplus and tariff revenues at two different levels of the world price of the exportable, $p^{*}$, holding the per unit tax, $T$, fixed. Note first that changes in $p^{*}$ affect the import-competing sector through changes in consumer surplus and tariff revenues (i.e, area $\mathrm{ABCD}$ minus the two Harberger triangles). Note further that change in surplus to this sector is a fixed proportion (i.e., the ratio $\theta$ ) of the overall change (since all individuals in this economy consume goods in identical fashion and get the same share of tax revenues). Thus, at a higher $p^{*}$, for a given $\mathrm{T}$, the change in surplus overall is higher (since $\mathrm{A}^{\prime} \mathrm{B}^{\prime} \mathrm{C}^{\prime} \mathrm{D}$ ' $>\mathrm{ABCD}$ and the Harberger triangles are the same area). This implies a higher change in surplus to the import lobby. Thus there is a greater incentive to lobby for a higher export tax, which results in a higher per unit export tax, T, in equilibrium. ${ }^{23}$

As we show in Appendix A.2., the third term $\frac{\partial \Delta_{e}}{\partial p^{*}}$ is always $\geq 0$ if $E_{s}^{\prime \prime} \geq 0$, a condition that we assume here but that can be argued to be satisfied under fairly general conditions. To see this we note first that the condition holds for the linear supply and demand case where, $E_{s}^{\prime \prime}=0$. Further, as we show in Appendix A.3., with constant export supply elasticities, for $E_{s}^{\prime \prime}>0$, we need that $\epsilon_{s}>1$ where $\epsilon_{s}$ denotes export supply elasticity. As we argue further in Appendix A.3., the condition that $\epsilon_{s}>1$ itself should be satisfied for a very wide range

\footnotetext{
${ }^{23}$ We should point out that this holds even under alternate assumptions regarding tariff revenue redistribution. To see this assume that the government holds onto tariff revenue instead of redistributing it uniformly to individuals. Now, with an increase in the world price of the exportable, the import-competing sector by itself would have less reason to lobby for an export tax (since its consumer surplus gain from such a tax on the margin is smaller). However, if it is assumed that the government places a premium on tariff revenues, then the government has a strong motivation to raise the export tax. On balance, with a strong enough emphasis on tax revenues placed by the government, the export tax would go up.
} 
of domestic supply and demand elasticities. ${ }^{24}$ Conditions under which $E_{s}^{\prime \prime} \geq 0$ holds even with non-constant export supply elasticities are discussed in Appendix A.3. as well.

Combining the three effects, we have that,

$$
\frac{d \mathbf{N B}}{d p^{*}}>0
$$

meaning that the net benefits to the export sector of forming an export lobby increase in $p^{*}$. This too can be seen from Figure I. Raising $p^{*}$, holding $T$ fixed, the export lobby sees a larger reduction in producer surplus ( A'B'C'D' instead of ABCD) thereby increasing the incentive of the export lobby to form a lobby and lobby against the tax. Further, as we have already explained, the per-unit export tax increases as $p^{*}$ goes up, increasing the incentive to form the lobby even further.

Now, knowing that

$$
\frac{d \mathbf{N B}}{d p^{*}}>0
$$

we let $p^{*}=\bar{p}$ solve the following equation:

$$
\mathbf{N B}\left(p^{*}\right)=F
$$

This allows us to state our third Proposition:

\section{Proposition 3}

When tariff reductions by the unilaterally liberalizing large country raise the world price $^{25}$ of the small country's exportable $\left(p^{*}\right)$ beyond $\bar{p}$, this unilateralism is recip-

\footnotetext{
${ }^{24}$ We should note here that even if we abandon our assumption regarding the curvature of the export supply function and it turns out to have the opposite sign (i.e., $E_{s}^{\prime \prime}<0$ ), $\mathbf{N B}$ would be increasing in $p^{*}$ if the product of the first and second terms (both unambiguously positive) dominates.

${ }^{25}$ With the specific assumptions on technology and preferences made here for the small country (and under identical assumptions for the large country), it is easy to show that we do not encounter the "Lerner case" and that a tariff reduction by the large country does increase the price of the small country's exportable in world markets.
} 
rocated: the small partner country moves to free trade.

This follows directly from equation (22) and equation (23). From these, we know that when $p^{*} \geq \bar{p}$, the exportable sector gets organized. Now with both export and import sectors organized, there is free trade. ${ }^{26}$

This establishes our primary result that unilateral liberalization by a large partner country within this framework will induce reciprocal liberalization. ${ }^{27}$ Profiles of the net benefit from lobby formation and the per unit trade taxes as functions of $p^{*}$ are illustrated in Figure II. As shown there, once the export price, $p^{*}$, rises above the threshold level, i.e., once $p^{*} \geq \bar{p}$, we have free trade. ${ }^{28}$

It is also useful to interpret the political-economy mechanism just stated in terms of how the welfare level of the exportable group varies with the world price of the exportable differently when this group is organized than when it is not. Figure III illustrates (see Appendix A.4. for the mathematical derivations) that an increase in the world price of the exportable increases welfare of the exportable group whether it is organized or unorganized. Thus, the welfare

\footnotetext{
${ }^{26}$ Note, interestingly, that this move towards free trade need not always be welfare improving for the partner country. Thus, imagine that the initial world price of the exportable is just below $\bar{p}$ and that unilateral liberalization by the large country raises it to a level just above $\bar{p}$, so that NB just exceeds $\mathrm{F}$. We know that the small country's export lobby would now form and in doing so will undertake a fixed resource cost of $\mathrm{F}$. Gross aggregate welfare goes up by $\left(\Delta_{m}+\Delta_{e}\right)$. However, the fixed cost would only be slightly below the net benefit to the export lobby which is given by $\mathbf{N B}=(a+1)\left(\Delta_{m}+\Delta_{e}\right)$ and is thefeore greater than $\left(\Delta_{m}+\Delta_{e}\right)$. Aggregate net welfare is thus lowered. However, our focus is, of course, on the large country's incentives to lower its tariffs unilaterally and on the positive analysis of the small country's response - an issue that we take up in detail in the next section.

${ }^{27}$ Note that in the model, unilateral liberalization by one country results in reciprocity by the partner country through changes in the "demand" for protection in the partner country. However, one could interpret this as occurring through a change in the "supply" of protection instead. Specifically, with the formation of the export lobby, the final maximand of the "supplier" of protection, the government, changes - since it now takes into account contributions by this lobby as well. One could therefore think of this, loosely, as being an endogenous change in preferences of the supplier of the protection.

${ }^{28}$ As can also be seen in Figure II, when $p^{*}$ is below the threshold level, the per unit export tax is rising with $p^{*}$ - just as we have discussed earlier.
} 
levels are shown with positive slopes. Note that the welfare level of the exportable group when organized (net of political contributions but gross of the fixed cost of lobby formation) is higher than when it is not organized. Note also that NB increasing in $p^{*}$ implies that the welfare locus when unorganized has flatter slope - implying, in turn, with large enough fixed costs, some point of intersection with the welfare locus when organized (net of both fixed costs and political contributions). The price at which this takes place is, again, $\bar{p}$. Beyond this price, the lobby is formed. Below it, it does not.

In the preceding discussion, in demonstrating the possibility that unilateral liberalization by a large country may induce reciprocity by its partner, we have made a number of explicit and implicit assumptions. The unilaterally liberalizing country was assumed to be large enough to affect world prices and, indeed reciprocal liberalization was shown to obtain only when tariff liberalization drove the world price $p^{*}$ above the threshold level, $\bar{p}$ (which, it may be noted, need not happen even with full liberalization by the large country). Further, in order for there to be some connection between export and import lobbies (crucial for the mechanism we have proposed), it was assumed that lobbies are large enough (i.e., that $\alpha$ is big enough) for lobby owners to care about the prices of goods they consume - although, as we have discussed before, this will be the case even if each lobby was small but used output from the other sector as an intermediate in its own production. A sufficiency condition regarding export supply elasticities was also stated and assumed to hold (and its empirical plausibility discussed). Finally, our analysis focused on the case where an active import lobby exists in the small country but there is no export lobby present. However, given (21), we can now discuss why our initial assumption regarding the pre-existence of the import-competing lobby rather than the exporting lobby is not crucial (see also section VI for a detailed discussion of alternate possibilities that emerge with different initial conditions): Taking the other group as organized, the net benefit from organizing for any group of specific factor owners is proportional to the total deadweight loss caused prior to its entry as an organized 
group. When the export sector is the only organized group, the deadweight loss created by this sector is increasing in the world price of the exportable as the per unit export subsidy increases with the world price of the exportable. This makes the net benefit from organizing for the second group (the import-competing lobby) increasing in the world price of the nonnumeraire exportable. This means that at a high enough world export price, we cannot have a single lobby equilibrium. In other words, if in the first stage, both groups decide on lobby formation simultaneously, we can only have a free-trade political economy equilibrium in the small open economy at a high enough export price (see section VI). ${ }^{29,30}$

\section{A Large Open Economy Facing A Large Number Of Small Open Economies}

How might the large country benefit from such a political-economy dynamic? Clearly, the (induced) movement of any single small country to free trade does not affect world prices and its liberalization of its trade regime is of little consequence to the large country. In keeping with one of our central motivating examples (discussed in the introduction) - the liberalization of the countries in North against each other and consequently (via GATT nondiscrimination) against the small southern economies - we analyze circumstances under which the large country (the North) may nevertheless benefit from the induced reciprocity in its small trading partners.

\footnotetext{
${ }^{29}$ It should be noted that although the per unit export tax in the small open economy increases with an increase in the world exportable price, this is not true about the ad valorem export tax, as can be seen from the equilibrium export tax expressions. For example, with a constant price elasticity of export supply, we have an ad valorem export tax that is decreasing in $p^{*}$. When we have linear demand and supply with the additional requirement that the supply passes through the origin, the ad valorem export tax remains constant. When this supply has a positive price intercept, the ad valorem tax is again decreasing in $p^{*}$.

${ }^{30}$ If the initial situation was one where no lobbies were organized, it is possible that a unilateral reduction in tariffs by the large country induces a single lobby to form - thus taking the small country away from its initial free trade regime. However, further reductions in tariffs should lead to the formation of the second lobby taking the small economy back to free trade.
} 
Specifically, we now consider a large open economy, $A$, trading with a continuum of small open economies. These small open economies are identical to each other with respect to technology, endowments and tastes and preferences. Let us call the entire mass of small open economies B. Let the total measure of this continuum be S. B's export (import) nonnumeraire good e (good m) is A's import (export) non-numeraire good. We assume also that the general structure of the "large" economy is similar to that of the small open economies with which it trades (even though it may differ from them in endowments and possibly the precise technologies used and in its exact preferences): Its consumers have quasi-linear and additively separable utility as in (1). It produces goods $x_{m}$ and $x_{e}$ using CRS technologies and employing sector specific capital and mobile labor and the numeraire good using Ricardian technology (just as in the small open economies).

Let $\beta$ denote the fraction of countries of type $\mathrm{B}$ in which both the import competing lobbies and the exporting lobbies are organized. Let $p_{e}^{*}\left(p_{m}^{*}\right)$ be the world equilibrium price of good $e(\operatorname{good} m)$. Let $t^{*}$ be A's ad valorem import tariff rate on $e$. We assume that the structure of each of the small open economies is the same as that of the small open economy in the previous section. We assume that A exogenously cuts (sets) its import tariff and in each of the small open economies, trade policy is set using political economy considerations as in Grossman-Helpman (1994). We will later determine A's optimal tariff in this framework. As shown in the previous section, in a small open economy, the net benefit from organizing for the export sector when the import competing sector is already organized is given by

$$
\mathbf{N B}=(a+1)\left(\Delta_{m}+\Delta_{e}\right)
$$

Let us first look at what a tariff reduction in A does to the incentives of the export interests to organize in a particular small open economy given the existence of an import lobby there and holding fixed $\beta$. Noting that in any country with an unorganized export lobby, the deadweight loss in the exportable sector can simply be expressed as a function of the 
exportable price ${ }^{31}$ and that the price of the exportable good is itself a function of A's tariff rate and $\beta$, we have,

$$
\frac{\partial \mathbf{N B}}{\partial t^{*}}=(a+1)\left[\frac{d \Delta_{e}}{d p_{e}^{*}} \cdot \frac{d p_{e}^{*}}{d t^{*}}\right]<0
$$

Next we look at how these incentives change as export sectors in more and more small open economies get organized. In other words, we look at the incentives for an export sector in a small open economy to get organized taking as given the fraction $\beta$ of the total mass of small open economies in which their respective non-numeraire sectors are organized and then look at how these incentives change as $\beta$ increases. We have,

$$
\frac{d \mathbf{N B}}{d \beta}=(a+1)\left[\frac{d \Delta_{m}}{d p_{m}^{*}} \cdot \frac{\partial p_{m}^{*}}{\partial \beta}+\frac{d \Delta_{e}}{d p_{e}^{*}} \cdot \frac{\partial p_{e}^{*}}{\partial \beta}\right]
$$

where the derivatives of the world prices with respect to $\beta$ take into account both its direct effect and the indirect effect on these prices through the "political economy" responses of the remaining "un-liberalized" small economies.

Signing the terms on the right hand side of (26) is done as follows: The first term on the right hand side is positive, since the per unit tariff goes up when the importable price goes up as a result of the rise in $\beta$. This implies that the sector's dead weight loss also goes up. ${ }^{32}$ The second term is negative since the exportable price goes down as a larger fraction of the

\footnotetext{
${ }^{31}$ In general, the deadweight loss would be a function of the export tax rate as well - but this can be dropped here since the export tax itself is endogenous to the price of the exportable good.

${ }^{32}$ This should be true (i.e., the first term is positive) as long as import demand is not too convex with respect to price. If the import demand is actually very convex, the first term would also be negative and all the analysis will be identical to case I.
} 
small open economies liberalize and as explained in the previous section, the associated dead weight loss would go up.

Due to the presence of the numeraire sector which is Ricardian and captures all the income effects in the additively separable, quasi-linear utility function, B can have greater market power in the world market for one non-numeraire good than in that for the other, thereby enabling a case by case analysis as follows.

Case I: B is large in the world market for $e$ and is small in the world market for $m$.

In this case, the second term in the previous equation dominates the first, so that NB is downward sloping with respect to $\beta$. This is shown in Figure IV. The NB curve shifts up as $t^{*}$ falls. The equilibrium fraction of the small open economies that liberalize is $\beta^{*}$ given by the intersection of the $\mathrm{NB}$ and the $\mathrm{F}$ curves. ${ }^{33}$ It is easy to see that $\beta^{*}$ goes up as $t^{*}$ falls. In other words, as the large open economy reduces its tariff, more and more small open economies liberalize. To see this think of the initial equilibrium as being at the point where the net benefit curve corresponding to tariff level $t_{1}$ intersects the fixed cost line denoted by F. If A's tariff is lowered to $t_{2}$, then the net benefit curve shifts up as shown. For the $\beta$ given by the initial equilibrium, net benefits now exceed the fixed costs and export lobbies are formed in more countries. Net benefits are higher than fixed costs all the way until the point where the new net benefit curve intersects the fixed cost line F. Here, we have a higher

\footnotetext{
${ }^{33}$ Of course, since all the small open economies are identical in structure, it is not possible to identify exactly which of these will have their export sectors organized. All we can analyze are the effects of different parameters on the "fraction" of these small open economies where the export sector will be organized and therefore, that undergo trade liberalization. However, if heterogeneity among these small open economies is introduced along one dimension at a time, one can identify which of the small open economies will organize. For example if organization costs differ across these economies, then economies which have fixed costs of export lobby formation below a certain cut off level will declare free trade with rest of the world and the ones above will not have free trade. Similarly, if these economies differ only in terms of their export capital stock, then there is going to be a cut off level of this capital. Small open economies which have export capital above this level will declare free trade.
} 
equilibrium level of $\beta$. At very high levels of A's tariff, no small open economy would have liberalized, while at very low levels, all of them would have.

Case II: B is large in the world market for $m$ and small in the world market for $e$.

In this case, the first term in the previous equation dominates the second term (which is zero), so that NB is upward sloping with respect to $\beta$. This is shown in Figure V. The NB curve shifts up as $t^{*}$ falls. The determination of equilibrium levels of $\beta$ is slightly more complicated than in the previous case. For intermediate values of $t^{*}$, we can see that there are multiple equilibria - either all the small open economies have liberalized or none of them has liberalized. The point where the NB curve intersects the F line is clearly unstable. However, for extreme values of A's tariff, the results are the same as in case I. When $t^{*}$ falls to a sufficiently low level, the entire NB curve is above F and all of the small countries have export lobbies and liberalize their trade regimes. This is the only equilibrium when $t^{*}$ is very low.

Case III: B is large in both markets.

In this case, we are not able to say which of the two terms in the previous equation dominates, so that the shape of NB with respect to $\beta$ cannot be unambiguously determined. However, for extreme values of A's tariff, the results would qualitatively be the same as in cases I and II. Therefore, all small open economies would still liberalize when A's tariff is very low, since then the NB curve could entirely be above F.

From the preceding analysis, we conclude that for large enough reductions in tariffs by the large country, reciprocal liberalization by the small open economies is likely. We now turn to the analysis of optimal tariffs for the large country. 


\section{The Large Open Economy's Optimal Tariff}

Having described, in the previous section, the political economy processes that would be set in motion with a unilateral liberalization by a large open economy trading with a number of small open economies, we now wish to investigate the implications of this for optimal (welfare maximizing) tariffs for the large country. ${ }^{34}$ Two points must be noted: We should note that we continue to assume that the general structure of the "large" economy is similar to that of the small open economies with which it trades (even though it may differ from them in its endowments and possibly the precise technologies used and in its exact preferences): Its consumers have quasi-linear and additively separable utility as in (1) and it produces goods $x_{m}$ and $x_{e}$ using CRS technologies and employing sector specific capital and mobile labor and the numeraire good using Ricardian technology (just as in the small open economies). Additionally, for the discussion that follows, we only allow the country the use of one trade instrument: an import tariff.

Let $W$ be the welfare of the large open economy. This can be expressed as a function of the large country's tariff $t^{*}$ and $\beta . \beta$ in turn is negatively related to $t^{*}$ as we have argued in Section V. ${ }^{35}$ Two situations may be contrasted:

(a)The large country chooses its tariffs taking the lobby structure in the rest of the world as fixed and where the lobbies in the small open economies, B, are formed taking the large country's tariff as given (i.e., with simultaneous moves) and

(b) The large country moves first, pre-committing to its tariff level, taking its effect on

\footnotetext{
${ }^{34}$ The welfare maximizing nature of the large country here is simply illustrative - our analysis of what the optimal tariffs should be holds independently of the actual process driving tariff determination in this large economy - be it welfare maximization or something else. Assuming welfare maximization here allows us to make the normative point that this section is devoted to.

${ }^{35}$ Note that this has to at least be true locally at a stable interior equilibrium. Here, it must be that the NB curve is downward sloping. From the equilibrium condition $\mathbf{N B}=\mathrm{F}$, we have that $\beta^{\prime}=-\frac{\partial \mathbf{N B} / \partial t^{*}}{\partial \mathbf{N B} / \partial \beta}$. Both the numerator and the denominator are less than zero, thus giving us that $\beta^{\prime}<0$.
} 
lobby formation in the home country into account (i.e. where the large country leads in Stackelberg-like fashion).

Thus, the timing of moves is as follows (See also Appendix A.5.): In the former (simultaneous moves) case, first, the large country's tariff and lobby structure in the small open economies are determined simultaneously, each taking the other as fixed. Then, in the next stage, the domestic trade policy vector is determined in the small open economies. In contrast, in the latter (Stackelberg) case, first the tariff choice is made by the large country and in the next stage lobbies in B are determined. Trade policies in B are determined in a final (third) stage. The only difference between the former and latter cases then is the fact that the latter case permits the large country to set tariffs taking into account the fact that its tariff will have implications for lobby formation decisions in the small open economies.

Thus, when we think of the simultaneous interaction between the large country and the small countries, we could think of the large country maximizing its welfare for a given level of $\beta$, so that we have $t^{*}=1 / \epsilon$. where $\epsilon$ denotes the elasticity of export supply from $\mathrm{B}$, (where the elasticity takes into account the fact that varying tariff levels for the tariff of the large open economy would result in varying levels of tariffs in B). This elasticity in turn depends on $t^{*}$ and $\beta$. Therefore, this gives us the large country's reaction function, which takes the form $t^{*}=t^{*}(\beta)$. We know the rest of the world's reaction function $\beta=\beta\left(t^{*}\right), \beta^{\prime}<0$. The point of intersection between the two reaction functions gives us the (Nash) equilibrium levels of tariff $t^{*}$ and fraction of small countries liberalized $\beta$. Let us call these levels $t_{n}^{*}$ and $\beta\left(t_{n}^{*}\right)$. In this equilibrium, beliefs and actions are consistent. In other words, the tariff level the small countries believe the large country will set is actually what it sets and similarly the $\beta$ the large country believes will prevail is actually what is realized. So, the large country does not take into account the fact that by moving first (relative to lobby formation in the partner countries) and credibly setting a certain tariff, it can affect the actual $\beta$. When 
this is done instead, we have the large country acting as a Stackelberg leader in the sense that it can move first and pre-commit to a certain tariff taking into account the effect of its tariff on the level of $\beta$. We now prove the following proposition:

\section{Proposition 4}

The large country's optimal (i.e., welfare maximizing) tariff is smaller when it takes into account its effect on the incentives for lobby formation in its partner countries than when it takes the lobby structure in the partner countries as given.

The large country's problem is

$$
\max _{t^{*}} W\left(t^{*}, \beta\left(t^{*}\right)\right)
$$

This gives us the following first-order condition:

$$
W_{1}+W_{2} \beta^{\prime}\left(t^{*}\right)=0
$$

Note that $W_{2} \beta^{\prime}\left(t^{*}\right)$ is always negative since, clearly, $W_{2}>0$ and $\beta^{\prime}<0$. Therefore, $W_{1}$ has to be positive for the above equality to hold. Let us write the above equation (27) as $\psi\left(t^{*}\right)=0$. The solution to this equation gives us the large country's optimal tariff when it acts as a leader. Let this solution be $t_{s}^{*}$. If we actually plug in $t_{n}^{*}$ into $\psi($.$) , this$ function would be negative, as $W_{1}=0$ at the Nash level. Using the second-order concavity condition, $\psi^{\prime}<0$, it is easy to see that $t_{s}^{*}<t_{n}^{*}$ to make $\psi=0$. This proves the proposition.

To see this in greater detail, we let $p_{e}^{*}\left(p_{m}^{*}\right)$ be the world equilibrium price of good $e$ (good $m$ ). Letting, again, $t^{*}$ be A's ad valorem import tariff rate on $e$, we have (See Appendix A.5. for details),

$$
W_{1}=t^{*} p_{e}^{*}\left[p_{e}^{*}+\left(1+t^{*}\right)\left(\partial p_{e}^{*} / \partial t^{*}\right)\right] M_{A}^{\prime}-\left(\partial p_{e}^{*} / \partial t^{*}\right) M_{A}
$$


where $M_{A}$ is country A's import demand for good $e$ as a function of the domestic price and $M_{A}^{\prime}$ is the derivative of this function with respect to the domestic price of $e$ in $A$.

Differentiating the condition that import demand equals export supply, we have

$$
\left(\partial p_{e}^{*} / \partial t^{*}\right) / p_{e}^{*}=-M_{A}^{\prime} /\left[\left(1+t^{*}\right) M_{A}^{\prime}-E_{B}^{\prime}\right]
$$

while $E_{B}$ is $B^{\prime} s$ export supply as a function of the world price at a given $\beta$ and $E_{B}^{\prime}$ is the derivative of $E_{B}$ with respect to $p_{e}^{*}$ at a given $\beta$. Using (28) and (29) and again equating $M_{A}$ to $E_{B}$ we have

$$
W_{1}=\left(\partial p_{e}^{*} / \partial t^{*}\right) M_{A}\left[t^{*} p_{e}^{*}\left(E_{B}^{\prime} / E_{B}\right)-1\right]=\left(\partial p_{e}^{*} / \partial t^{*}\right) M_{A}\left[t^{*} \epsilon-1\right]
$$

Of course, $W_{1}=0$ implies $t_{n}^{*}=1 / \epsilon$ where $\epsilon=p_{e}^{*}\left(E_{B}^{\prime} / E_{B}\right)$, where the export supply curve for B is itself a function of A's import tariffs.

$$
W_{1}+W_{2} \beta^{\prime}\left(t^{*}\right)=0 \text { instead implies } t_{s}^{*}=\left\{(1 / \epsilon) \frac{W_{2} \beta^{\prime}}{-M_{A}\left(\partial p_{e}^{*} / \partial t^{*}\right)}\right\}+1 / \epsilon
$$

$W_{2}>0, \beta^{\prime}<0,\left(\partial p_{e}^{*} / \partial t^{*}\right)<0$ which imply that the first term in the above equation is negative. (31) thus shows that the optimal tariff is lower when the large country takes into account its effect on the lobby structure in the home country.

\section{Simulations}

Thus far, our argument regarding reciprocated unilateralism has been discussed in the context of particular (and, as we shall argue further below, empirically relevant) initial conditions. Specifically, the argument has been developed in the context of a small trading partner whose trade policy has been distorted due the exclusive initial presence of an import- 
competing lobby. A question arises here as to what happens under other different initial conditions. That is to say, what will be the effect of unilateral tariff liberalization by the large country if no lobbies are present in the small country initially? Or if it is an export lobby rather than an import lobby that is initially present? The complexity of the theoretical framework and multitude of parameters involved make analytical solutions to these questions hard to obtain and assess. However, simulation analysis using alternative functional forms and parameter values (treating the political organization decision of both the export and the import-competing lobby as endogenous) provides us with guidance on this issue. We discuss our findings below.

Our discussion of our findings using simulation analysis focuses on two illustrative cases. In both, demand functions and production functions are assumed to be linear and symmetric across sectors (see Appendix A.6. for details). We develop some additional notation as follows. $F N B_{i}()=N B-F$ denotes the full net benefit (benefit from organizing net of contributions and fixed costs) with the subscript $i=m, e$ indicating the sector whose full net benefit function it is. Included within the parentheses are all the sectors which are organized once the sector under consideration gets organized (for example, $F N B_{e}(e)$ denotes the full net benefit to the export sector from forming its lobby when the import-competing lobby is not organized, and $F N B_{e}(m, e)$ denotes the full net benefits to the export sector from lobby formation when the import-competing sector is organized as well). To see the effects of unilateral tariff reductions by the large country, we hold the import price of the small open economy constant at unity and vary the export price, $p^{*}$.

In our first case (Figure VI), our small open economy is assumed to have an endowment of capital (sector specific) in the exportable sector that is twice the amount of capital in the import-competing sector. As we have maintained throughout this analysis, individuals in this economy are assumed to own capital in identical amounts and in one or the other of 
the two sectors (but not both). Assuming further that the fixed cost of lobby organization, $F$, is proportional to the number of capital owners in a sector, we take the fixed cost of political organization in the export sector to be twice that in the import-competing sector. Figure VI presents the full net benefit curves as a function of the export price faced by the small open economy. The slopes of the full net benefit curves are positive for reasons that have already been discussed earlier in this paper. We can see from Figure VI that for low values of the export price, we have a unique equilibrium with just the import sector organized. As the export price rises, this initially continues to be the unique equilibrium - the FNB curves for the export sector (taking the import sector to be organized or not) are both below zero and the $F N B$ curves for the import sector are both above zero. After $F N B_{e}(m, e)$ rises above zero with yet higher $p^{*}$, the export lobby gets formed and the unique equilibrium here involves the formation of both lobbies (with free trade as the trade policy outcome) since $F N B$ curves for both lobbies, each taking the other as organized, are above zero. This scenario is consistent with the one that we have focused on in the paper so far and illustrates our main argument. Note, however, that if fixed costs were a bit higher in the import-competing sector, both the $F N B_{m}$ curves would shift down uniformly and, at low values of $p^{*}$, the import-competing sector would not be organized. If this were the initial condition, a reduction in tariffs by the large country would now induce the import-competing lobby to form first - a change in economic circumstances that would be welfare decreasing since agents in the small economy will have moved from an efficient trade regime (with free trade) to an inefficient one having incurred additionally the fixed costs of lobby formation. This may appear as damaging to the argument regarding the use of unilateralism to induce reciprocity, but this is not the case since, of course, the argument is only relevant when there are some tariffs being imposed by the partner country in the first place. Also, with further tariff reductions (i.e., increases in the world price, $p^{*}$ ), the export lobby gets formed as well (after $F N B_{e}$ goes above zero) and we have free trade. Thus, with high enough tariff 
reductions by the large country, free trade obtains in the partner country (even if the path to this is non-monotonic and fixed costs of lobby organization have been incurred along the way).

In our second case, we continue to assume that the endowment of capital in the exportable sector is twice than in the importable sector. However, fixed costs of lobby organization for the export sector are assumed to be lower than that in the importable sector. As shown in Figure VII, this gives us $F N B$ curves for the exportable that are higher than those in the importable sector. Note that, as drawn, at low levels of $p^{*}$, it is now the export lobby that is organized while the import lobby is not. Trade policy is initially distorted with export subsidies and import subsidies. While it should be clear that this is an empirically nearly irrelevant case as virtually no countries can be characterized as having trade regimes of this nature, it is a clear theoretical possibility and so we analyze this nonetheless. Here too, a high enough increase in the world price of the exportable results in the formation of the import lobby with free trade emerging as the policy outcome. While such an outcome would benefit the small country (if the welfare gain from the move to the undistorted policy regime outweighed the fixed costs of lobby formation), the large country would be faced with a policy regime less favorable to it. Finally, if fixed costs were a little higher, there would be no lobbies at low values of $p^{*}$. An increase in $p^{*}$ would first lead to the formation of an export lobby which would be welfare worsening for the small country, causing it to move from free trade to a trade regime that was more favorable to the large country. Of course, further increases in $p^{*}$, as shown, will cause the formation of the import lobby as well and a movement back to free trade. ${ }^{36}$

\footnotetext{
${ }^{36}$ We should note another interesting possibility that emerges in the setting just discussed. When only the import lobby is organized initially, an increase in tariffs by the large country also reduces the benefit to the import lobby of being active, as the FNB profiles show. To the extent that fixed costs of lobby organization are paid period by period, this suggests that tariff increases by the large country may also move the small country to free trade (if the import lobby drops out). However, if lobby organization costs are fully sunk, there will always be an incentive for the import sector to lobby (however small). The possibility of unilateral
} 
Finally, we should note that, for particular parameter values, other possibilities than those discussed in the two cases above arise as well. Specifically, with increases in $p^{*}$, it may be that we enter an intermediate zone where multiple equilibria are possible. Thus, the position of the FNB curves may be such that each lobby has an incentive to get organized only if the other lobby does as well. The outcome could then either be that both lobbies get organized or that neither does (with free trade as the policy outcome either way). In these cases too, however, it can be seen that with large enough values of $p^{*}$ both lobbies get organized -

The simulations exercises, which examine a variety of "initial conditions," leave us with the following conclusions. First, the argument regarding reciprocated unilateralism has normative relevance primarily in contexts where the unilaterally liberalizing country faces countries that impose restrictions on its exports. Second, sufficiently large unilaterally tariff reductions lead to free trade in the partner countries regardless of the initial conditions.

\section{Summary and Conclusions}

Using the menu-auction approach to endogenous determination of tariffs pioneered by Grossman and Helpman (1994) and allowing for lobby formation itself to be endogenous, as in Mitra (1999), this paper analyzes the potential for unilateral trade liberalization by one country to impact trade policies in its partner in the absence of any formal agreement or communication between these countries.

We consider a large country trading with a small partner in which initially an organized import-competing lobby exists and where the trade regime is characterized by import tariffs (and export taxes). In this context, we find that unilateral liberalization by the large country will induce reciprocal tariff reductions by altering the political economy equilibrium there. Intuitively, unilateral liberalization by the large country has the effect of increasing the increases in tariffs by the large country leading to free trade in the partner then disappears. 
incentives for the export lobby in the partner country to form and to lobby effectively against the import-competing lobbies there for lower protection. Using simulation analysis, we confirm that large enough tariff reductions by the large country will induce the small country to move towards free trade even under quiet different initial conditions than the ones considered above (although the path towards free trade may not always be monotonic, as we have discussed in section VII).

The induced reciprocity mechanism we have discussed has potentially important normative implications. Optimal tariffs that anticipate such reciprocity in partners may be lower than those calculated ignoring this reciprocity mechanism. 


\section{Appendix}

A.1. To prove: $\frac{d T}{d p^{*}}>0$.

Proof: From(15) and (16), when only the import-competing sector is organized, the ad valorem import tax and the ad valorem export tax are given by: $t_{m}=\frac{1-\theta}{a+\theta} \cdot \frac{x_{m}\left(p_{m}\right)}{\left[-p_{m}^{*} I_{m}^{\prime}\left(p_{m}\right)\right]}$ and $t_{e}=\frac{-\theta}{a+\theta} \cdot \frac{x_{e}\left(p_{e}\right)}{\left[-p_{e}^{*} I_{e}^{\prime}\left(p_{e}\right)\right]}$ respectively,

where $I_{m}\left(p_{m}\right)$ is import demand and $-I_{e}\left(p_{e}\right)$ is export supply. Normalizing $p_{m}^{*}=1$ and letting $p_{e}^{*}=p^{*}$, we can write the magnitude of the per unit export tax as

$$
T=\left|p^{*} t_{e}\right|=\frac{\theta}{a+\theta} \cdot \frac{x_{e}\left(p_{e}\right)}{\left[-I_{e}^{\prime}\left(p_{e}\right)\right]}=g\left(p^{*}-T\right) .
$$

We impose the restriction that an increase in the price of a commodity should increase the output supplied proportionally more than it increases the magnitude of the derivative of export supply with respect to price, so that $g^{\prime}>0$. This would always hold for linear demand and supply functions and also for most standard demand and supply functions.

Differentiating $T$ with respect to $p^{*}$,

$$
\frac{d T}{d p^{*}}=\frac{g^{\prime}}{1+g^{\prime}}>0 .
$$

A.2. Sufficient Condition for $\frac{\partial \Delta_{e}}{\partial p^{*}}>0, E_{S}^{\prime \prime}(p) \geq 0$

From Figure VIII, we have deadweight loss in the exportable sector due to the export tax given as:

$$
\begin{aligned}
\Delta\left(T, p^{*}\right) & =\int_{p^{*}-T}^{p^{*}} E_{S}(p) d p-T E_{S}\left(p^{*}-T\right) \\
& =I E_{S}\left(p^{*}\right)-I E_{S}\left(p^{*}-T\right)-T E_{S}\left(p^{*}-T\right)
\end{aligned}
$$


where $I$ stands for integral evaluated at a particular value.

$$
\begin{aligned}
\Delta_{2}\left(T, p^{*}\right) & =E_{S}\left(p^{*}\right)-E_{S}\left(p^{*}-T\right)-T E_{S}^{\prime}\left(p^{*}-T\right) \\
\Delta_{2} \geq 0 & \Leftrightarrow \quad E_{S}\left(p^{*}\right)-E_{S}\left(p^{*}-T\right) \geq T E_{S}^{\prime}\left(p^{*}-T\right) \\
& \Leftrightarrow \frac{E_{S}\left(p^{*}\right)-E_{S}\left(p^{*}-T\right)}{T} \geq E_{S}^{\prime}\left(p^{*}-T\right) .
\end{aligned}
$$

By the mean value theorem,

$$
\begin{aligned}
& \text { there exists } p^{\prime} \in\left[p^{*}-T, p^{*}\right], \quad \text { such that } \\
& \frac{E_{S}\left(p^{*}\right)-E_{S}\left(p^{*}-T\right)}{T}=E_{S}^{\prime}\left(p^{\prime}\right)
\end{aligned}
$$

where, $p^{\prime} \geq p^{*}-T$.

Therefore,

$$
E_{S}^{\prime \prime}(p) \geq 0 \Rightarrow E_{S}^{\prime}\left(p^{*}-T\right) \leq E_{S}^{\prime}\left(p^{\prime}\right)=\frac{E_{S}\left(p^{*}\right)-E_{S}\left(p^{*}-T\right)}{T}
$$

which in turn implies that $\Delta_{2} \geq 0$.

On Necessary and Sufficient Conditions:

$$
\begin{aligned}
\frac{d \Delta}{d p^{*}} & =\Delta_{1} \frac{d T}{d p^{*}}+\Delta_{2} \\
& =\left[E_{S}\left(p^{*}-T\right)-E_{S}\left(p^{*}-T\right)+T E_{S}^{\prime}\left(p^{*}-T\right)\right] \frac{d T}{d p^{*}} \\
& +\left[E_{S}\left(p^{*}\right)-E_{S}\left(p^{*}-T\right)-T E_{S}^{\prime}\left(p^{*}-T\right)\right] \\
& =\underbrace{T E_{S}^{\prime}\left(p^{*}-T\right) \frac{d T}{d p^{*}}}_{+}+\underbrace{\left[E_{S}\left(p^{*}\right)-E_{S}\left(p^{*}-T\right)-T E_{S}^{\prime}\left(p^{*}-T\right)\right.}_{+/-}]
\end{aligned}
$$

We know that $E_{S}^{\prime \prime} \geq 0$ is a sufficient condition for $\frac{d \Delta}{d p^{*}}>0$, since it makes the second term $\geq 0$. With $E_{S}^{\prime \prime}<0$, the second term is negative. However, we can still have $\frac{d \Delta}{d p^{*}}>0$ as long as the first-term dominates the second. In other words, we only need the total on the 
right hand side of the above expression to be $>0$ as a necessary and sufficient condition for $\frac{d \Delta}{d p^{*}}>0$. This is less restrictive then $E_{S}^{\prime \prime} \geq 0$ which is a sufficient condition.

\section{A.3. Export Supply Elasticities}

The export supply elasticity can be expressed as $\epsilon_{s}=\frac{p}{E_{s}(p)} E_{s}{ }^{\prime}(p)$. Twice differentiating $E_{s}(p)$ and requiring it to be non-negative, i.e., requiring, $E_{s}^{\prime \prime} \geq 0$,

in turn requires that $\frac{\epsilon_{s}}{p}\left[\epsilon_{s}-1\right]+\frac{\partial \epsilon_{s}}{\partial p} \geq 0$,

which finally can be expressed as: $\frac{p}{\epsilon_{s}} \frac{\partial \epsilon_{s}}{\partial p} \geq-\left[\epsilon_{s}-1\right]$. Note that with constant export supply elasticities, this translates into the requirement that $\epsilon_{s} \geq 1$. For non-constant export supply elasticity, $E_{s}{ }^{\prime \prime} \geq 0$ requires that the elasticity of the elasticity of export supply not be too negative when $\epsilon_{s} \geq 1$ and that it be above a certain positive value, $1-\epsilon_{s}$, when $\epsilon_{s}<1$.

When is $\epsilon_{s} \geq 1$ ? The export supply elasticity can alternately be expressed as:

$$
\epsilon_{s}=\frac{x}{x-c} \epsilon_{x}+\frac{c}{x-c} \epsilon_{c}
$$

where $\epsilon_{x}$ and $\epsilon_{c}$ denote absolute values of the elasticity of domestic output supply and demand for the exportable good. It is easy to see that $\epsilon_{s} \geq 1$ would hold with most reasonable values of the domestic supply and demand elasticities and ratios of consumption to production of this good. Indeed, for the converse to be true, one would need to have very low elasticities of domestic demand and supply of the exportable and very small ratios of domestic consumption relative to output.

\section{A.4.}

Let $p_{e}$ and $p_{m}$ be the domestic prices of the export and import goods respectively. When only the import sector is organized, the government maximizes the following objective 
function with respect to $p_{e}$ and $p_{m}$ :

$$
\begin{aligned}
& \Omega^{m}\left(p_{e}, p_{m}, p^{*}\right)+a \Omega^{A}\left(p_{e}, p_{m}, p^{*}\right) \\
& =(a+1) \Omega^{m}\left(p_{e}, p_{m}, p^{*}\right)+a \Omega^{e}\left(p_{e}, p_{m}, p^{*}\right) \\
& =(a+1) \pi_{m}\left(p_{m}\right)+a \pi_{e}\left(p_{e}\right)+(a+\theta)\left[C T_{m}\left(p_{m}\right)+C T_{e}\left(p_{e}, p^{*}\right)\right]+(a+\theta) N l, \text { where } C T_{i}
\end{aligned}
$$

is consumer surplus plus tax revenue generated by sector $i$, while $\pi_{i}$ is profit accruing to sector $i$.

From the above maximization exercise, we have the following first-order conditions:

$$
\begin{gathered}
(a+1) \pi_{m}^{\prime}\left(p_{m}\right)+(a+\theta) C T_{m}^{\prime}\left(p_{m}\right)=0 \\
a \pi_{e}^{\prime}\left(p_{e}\right)+(a+\theta) C T_{e 1}\left(p_{e}, p^{*}\right)=0
\end{gathered}
$$

where the subscript " 1 " denotes the partial derivative with respect to the first argument.

The equilibrium welfare level of the export group when only the import-competing sector is organized is given by $\tilde{\Omega}_{m}^{e}\left(p^{*}\right)=\pi_{e}\left(\tilde{p}_{e}\right)+(1-\theta)\left[C T_{e}\left(\tilde{p}_{e}, p^{*}\right)+C T_{m}\left(\tilde{p}_{m}\right)\right]$ where $\tilde{p}_{i}$ is the equilibrium domestic price of good $i$ when only the import-competing sector is organized.

Totally differentiating with respect to $p^{*}$, we have

$$
\tilde{\Omega}_{m}^{e^{\prime}}\left(p^{*}\right)=\left[\pi_{e}^{\prime}\left(\tilde{p}_{e}\right)+(1-\theta) C T_{e 1}\left(\tilde{p}_{e}, p^{*}\right)\right] \frac{d \tilde{p}_{e}}{d p^{*}}+(1-\theta) C T_{e 2}\left(\tilde{p}_{e}, p^{*}\right)
$$

where the subscripts "1" and " 2 " denote partial derivatives with respect to the first and second arguments respectively.

From (II), we have $C T_{e 1}\left(\tilde{p}_{e}, p^{*}\right)=\frac{-a}{a+\theta} \pi_{e}^{\prime}\left(\tilde{p}_{e}\right)$ which when plugged into (III) yields

$$
\tilde{\Omega}_{m}^{e^{\prime}}\left(p^{*}\right)=\frac{(1+a) \theta}{(a+\theta)} \pi_{e}^{\prime}\left(\tilde{p}_{e}\right) \frac{d \tilde{p}_{e}}{d p^{*}}+(1-\theta) C T_{e 2}\left(\tilde{p}_{e}, p^{*}\right)
$$

We know that $\frac{d \tilde{p}_{e}}{d p^{*}}=\frac{d\left(p^{*}-T\right)}{d p^{*}}=1-\frac{g^{\prime}}{\left(1+g^{\prime}\right)}=\frac{1}{\left(1+g^{\prime}\right)}>0$ where $g(\cdot)$ is defined as before in the appendix.

$$
C T_{e}=C S_{e}+T R_{e}\left(p_{e}, p^{*}\right)=C S_{e}\left(p_{e}\right)+\left(p^{*}-p_{e}\right)\left[x_{e}\left(p_{e}\right)-D_{e}\left(p_{e}\right)\right]
$$


where $C S_{e}$ and $T R_{e}$ are consumer surplus and export tax revenue respectively generated by the export sector and $D_{e}$ is the domestic demand for the export good.

Therefore, we have $C T_{e 2}=\left[x_{e}\left(p_{e}\right)-D_{e}\left(p_{e}\right)\right]>0$. Hence, $\tilde{\Omega}_{m}^{e^{\prime}}\left(p^{*}\right)>0$ which means that the welfare of the export sector when unorganized in the presence of an organized importcompeting sector is increasing with respect to the world export price. This is shown by the

positive slope of this graph in Figure III. $\tilde{\Omega}_{m, e}^{e^{\prime}}-\tilde{C}^{\prime}\left(p^{*}\right)=\tilde{\Omega_{m}^{e^{\prime}}}\left(p^{*}\right)+(a+1) \frac{d \Delta_{e}}{d p^{*}}>\tilde{\Omega_{m}^{e^{\prime}}}$. Also $\tilde{\Omega}_{m, e}^{e}\left(p^{*}\right)-\tilde{C}\left(p^{*}\right)=\tilde{\Omega_{m}^{e}}\left(p^{*}\right)+(a+1)\left(\Delta_{e}+\Delta_{m}\right)>\tilde{\Omega}_{m}^{e}\left(p^{*}\right)$. This, in turn, means that when organized the welfare of the export group, net of political contributions but gross of fixed costs is both higher and more steeply sloped that its welfare when its is not organized (see Figure III). With fixed costs large enough, the welfare of the organized export group both net of fixed costs and political contributions will be below the unorganized welfare curve for low values of $p^{*}$, but above it for high values.

A.5. Derivation of (28), (29), (30) and (31).

The various stages under the two situations (Simultaneous Moves and Stackelberg) are given by

\section{Simultaneous Move}

Stage 1: $t^{*}$ is chosen by $A$ and lobbies in $\mathrm{B}$ are determined simultaneously

Stage 2: The domestic trade taxes and subsidies are determined in $B$

\section{Stackelberg}

Stage 1: $t^{*}$ is chosen by $A$

Stage 2: Lobbies in $B$ are determined

Stage 3: Trade Policy is determined in B 
Given quasi-linear utility, aggregate welfare in country A can be given as

$$
W_{A}=W_{e}+W_{m}+Y_{L}
$$

where

$W_{e}: \quad$ consumer surplus $(\mathrm{CS})+$ producer surplus $(\mathrm{PS})+$ trade tax revenue $(\mathrm{TR})$ generated by the "e" sector (country A's importable sector, i.e., B's exportable) in country A

$W_{m}: C S+P S+T R$ generated by the "m" sector in country A

$Y_{L}: \quad$ Labor income

Here, $W_{1}$, of $(27)$, is given as:

$$
W_{1}=\frac{\partial W}{\partial t^{*}}=\frac{\partial W_{e}}{\partial t^{*}}
$$

where,

$$
W_{e}=\int_{p_{e}^{*}(1+t)}^{\infty} D_{e}(p) d p+\pi\left(p_{e}^{*}\left(1+t^{*}\right)\right)+\left[D_{e}-X_{e}\right] t^{*} p_{e}^{*}
$$

where,

$D_{e}$ : country A's $d d$ for " $e$ "

$X_{e}$ : country A's ss for " $e$ "

This can be re-written as:

$$
W_{e}=I D_{e}(\infty)-I D_{e}\left(p_{e}^{*}\left(1+t^{*}\right)\right)+\pi\left(p_{e}^{*}\left(1+t^{*}\right)\right)+\left[D_{e}-X_{e}\right] t^{*} p_{e}^{*}
$$


where I stands for the integral evaluated at a particular point.

$$
\begin{aligned}
\frac{\partial W_{e}}{\partial t^{*}} & =-D_{e}\left[p_{e}^{*}+\left(1+t^{*}\right) \frac{\partial p_{e}^{*}}{\partial t^{*}}\right]+X_{e}\left[p_{e}^{*}+\left(1+t^{*}\right) \frac{\partial p_{e}^{*}}{\partial t^{*}}\right] \\
& +t^{*} p_{e}^{*}\left[D_{e}^{\prime}-X_{e}^{\prime}\right]\left[p_{e}^{*}+\left(1+t^{*}\right) \frac{\partial p_{e}^{*}}{\partial t^{*}}\right]+\left[D_{e}-X_{e}\right]\left[p_{e}^{*}+t^{*} \frac{\partial p_{e}}{\partial t^{*}}\right] \\
& =-M_{A} \frac{\partial p_{e}^{*}}{\partial t^{*}}+t_{e}^{*} p_{e}^{*} M_{A}^{\prime}\left[p_{e}^{*}+\left(1+t^{*}\right) \frac{\partial p_{e}^{*}}{\partial t^{*}}\right]
\end{aligned}
$$

The above expression is Equation (28) in the text.

Note that,

$$
M_{A}=D_{e}-X_{e}
$$

Import Demand = Export Supply

$$
\Rightarrow M_{A}\left(p_{e}^{*}\left(1+t^{*}\right)\right)=E_{B}\left(p_{e}^{*}\right)
$$

Differentiating both sides w.r.t. $t^{*}$,

$$
\begin{aligned}
M_{A}^{\prime}\left[p_{e}^{*}+\left(1+t^{*}\right) \frac{\partial p_{e}^{*}}{\partial t^{*}}\right]=E_{B}^{\prime} \frac{\partial p_{e}^{*}}{\partial t^{*}} & \Rightarrow M_{A}^{\prime} p_{e}^{*}=\left[-\left(1+t^{*}\right) M_{A}^{\prime}+E_{B}^{\prime}\right] \frac{\partial p_{e}^{*}}{\partial t^{*}} \\
& \Rightarrow \frac{-M_{A}^{\prime}}{\left(1+t^{*}\right) M_{A}^{\prime}-E_{B}^{\prime}}=\frac{1}{p_{e}^{*}} \frac{\partial p_{e}^{*}}{\partial t^{*}}
\end{aligned}
$$

The above equation is equation (29) in the text.

$$
\begin{aligned}
W_{1} & =\frac{\partial W_{e}}{\partial t^{*}}=-M_{A} \frac{\partial p_{e}^{*}}{\partial t^{*}}+t^{*} p_{e}^{*} M_{A}^{\prime}\left[p_{e}^{*}+\left(1+t^{*}\right) \frac{\partial p_{e}^{*}}{\partial t^{*}}\right] \\
& =\frac{\partial p_{e}^{*}}{\partial t^{*}} M_{A}\left\{t^{*} p_{e}^{*}\left[\frac{p_{e}^{*}}{\frac{\partial \partial_{e}^{*}}{\partial t^{*}}}+\left(1+t^{*}\right)\right] \frac{M_{A}^{\prime}}{M_{A}}-1\right\}
\end{aligned}
$$


Using (28) and (29), we have

$$
\begin{aligned}
W_{1} & =\frac{\partial p_{e}^{*}}{\partial t^{*}} M_{A}\left\{t^{*} p_{e}^{*}\left[\frac{\left(1+t^{*}\right) M_{A}^{\prime}-E_{B}^{\prime}}{-M_{A}^{\prime}}+\left(1+t^{*}\right)\right] \frac{M_{A}^{\prime}}{M_{A}}-1\right\} \\
& =\frac{\partial p_{e}^{*}}{\partial t^{*}} M_{A}\left\{\frac{t^{*} p_{e}^{*} E_{B}^{\prime}}{M_{A}}-1\right\}
\end{aligned}
$$

This is Equation (30) in the text. Noting that Import demand = export supply, we have:

$$
M_{A}=E_{B}
$$

Substituting this back into the expression for $W_{1}$, gives us:

$$
\Rightarrow W_{1}=\frac{\partial p_{e}^{*}}{\partial t^{*}} M_{A}\left\{\frac{t^{*} p_{e}^{*} E_{B}^{\prime}}{E_{B}}-1\right\}=\frac{\partial p_{e}^{*}}{\partial t^{*}} M_{A}\left\{t^{*} \epsilon-1\right\}
$$

From (27), we have:

$$
\begin{aligned}
& \text { FOC }: W_{1}+W_{2} \beta^{\prime}\left(t^{*}\right)=0 \\
\Rightarrow & \frac{\partial p_{e}^{*}}{\partial t^{*}} M_{A}\left\{t^{*} \epsilon-1\right\}+W_{2} \beta^{\prime}\left(t^{*}\right)=0 \\
\Rightarrow & t^{*} \epsilon-1=\frac{W_{2} \beta^{\prime}}{-M_{A}\left[\frac{\partial p_{e}^{*}}{\partial t^{*}}\right]} \\
\Rightarrow & t^{*} \epsilon=\frac{W_{2} \beta^{\prime}}{-M_{A}\left[\frac{\partial p_{e}^{*}}{\partial t^{*}}\right]}+1 \\
\Rightarrow & t^{*}=\left[\frac{1}{\epsilon}\right]\left[\frac{W_{2} \beta^{\prime}}{-M_{A}\left[\frac{\partial p_{e}^{*}}{\partial t^{*}}\right]}\right]+\frac{1}{\epsilon}
\end{aligned}
$$

The above expression is simply equation (31) in the text. The export supply function of $\beta$ here is a function of $p^{*}$ and $\beta$. The effect of $p^{*}$ here incorporates the direct effect of $p^{*}$ on export supply as well as the indirect effect through its effect on the export tax in the " $\beta$ " small open economies for a given $\beta$. One should note here that the political economy equilibrium domestic price of the export sector (given the number of lobbies) is always increasing the world price $p_{e}^{*} \cdot{ }^{37}$

${ }^{37}$ It is important to note throughout that $E_{S}^{\prime}$ here is $\frac{\partial E_{S}}{\partial p_{e}^{*}}\left(p_{e}^{*}, \beta\right)$. In other words, $\beta$ is held constant. However, the political economy reactions of countries in $\mathrm{B}$ is taken into account. 
A.6.

To conduct the simulation analysis, we make the following assumptions regarding supply and demand functions in the small economy: Total endowment of the export-specific capital in the economy is assumed to be twice that of the import-competing specific factor. The production functions of the two goods are assumed to be the same, so that, taking into account the endowment difference, we can write the supply functions of the exportable and import-competing goods respectively as $x_{e}=2 * p_{e}$ and $x_{m}=p_{m}$. We also write the aggregate domestic demands as $A_{e}-p_{e}$ and $A_{m}-p_{m}$. 


\section{References}

Aumann, R., 1959, "Acceptable Points in General Cooperative n-Person Games," in Contributions to the Theory of Games IV, Princeton University Press, Princeton, NJ.

Bagwell, K., and Staiger, R., 1999, "An Economic Theory of GATT”, American Economic Review.

Becker, G., 1983, "A Theory of Competition Among Pressure Groups for Political Influence," Quarterly Journal of Economics 97.

Bernheim, B. Douglas and Michael D. Whinston, 1986, "Menu Auctions, Resource Allocation, and Economic Influence," Quarterly Journal of Economics, February.

Bernheim, B. Douglas, B. Peleg and Michael D. Whinston, 1987, "Coalition-Proof Nash Equilibria," Journal of Economic Theory, June.

Bhagwati, J., 1991, "Fair Trade, Reciprocity and Harmonization: The New Challenge to the Theory and Policy of Free Trade", Columbia University Working Paper Number 604.

Bhagwati, J., 1990, "Aggressive Unilateralism" in Bhagwati, J., and Patrick, H., eds., Aggressive Unilateralism, Ann Arbor, MI: University of Michigan Press.

Bhagwati, J., and Feenstra, R., 1982, "Tariff Seeking and The Efficient Tariff", in Bhagwati, J., ed., Import Competition and Response, Chicago, IL: University of Chicago Press.

Bhagwati, J., and Irwin. D., 1987, "The Return of the Reciprotarians: US Trade Policy Today", World Economy, 10(2), pp 109-130.

Coates, D., and Ludema, R., 1997, "Unilateral Trade Liberalization as Leadership in Trade Negotiations", Mimeo, Georgetown University.

Dixit, A., Grossman, G. and Helpman, E., 1997, "Common Agency and Coordination: General Theory and Application to Government Policy Making," Journal of Political Economy, August.

De Melo, J., Grether, J. and Olarreaga, M., 2001, "Who determines Mexican trade policy?," Journal of Development Economics.

Findlay, R. and Wellisz, S., 1982, "Endogenous Tariffs, the Political Economy of Trade Restrictions and Welfare," in J.N. Bhagwati, ed., Import Competition and Response, Chicago and London: The University of Chicago Press. 
Goldstein, M., and Khan, M., 1985, "Income and Price Effects in International Trade", in Jones and Kenen eds., Handbook of International Economics, Volume 2, North Holland.

Grossman, G. and Helpman, E., 1994, "Protection for Sale," American Economic Review, September.

Grossman, G. and Helpman, E., 1995a, "Trade Wars and Trade Talks," Journal of Political Economy, August.

Grossman, G. and E. Helpman, E., 1995b, "The Politics of Free Trade Agreements," American Economic Review, September.

Helpman, E., 1995, "Politics and Trade Policy," The Eitan Berglas School of Economics, Tel-Aviv University Working Paper No. 30-95, September.

Helpman, E. and Persson, T., 1998, "Lobbying and Legislative Bargaining," NBER Working Paper, Number 6589.

Hillman, A., 1982, "Declining Industries and Political-Support Protectionist Motives", American Economic Review, December, 72(5), pp 1180-87.

Hillman, A., and Moser, P., 1996, "Trade Liberalization as Politically Optimal Exchange of Market Access," in Canzoneri et al (eds), The New Transatlantic Economy, Cambridge University Press, Cambridge, UK, 295-316.

Hillman, A., and Ursprung, Heinrich, W., 1988, "Domestic Politics, Foreign Interests and International Trade Policy", American Economic Review, 78(4), pp 729-45.

Irwin, D., and Kroszner, R., 1997, Interests, Institutions and Ideology in the Republican Conversion to Trade Liberalization, 1934-1945, Working Paper, NBER.

Johnson, H., 1953, "Optimum Tariffs and Retaliation", Review of Economic Studies, 21, $142-53$.

Kindleberger, C., 1975, "The Rise of Free Trade in Western Europe, 1820-1875," Journal of Economic History, 20-55.

Kindleberger, C., 1977, America in the World Economy, New York; Foreign Policy Association.

Krueger, A., 1974, "The Political Economy of the Rent-Seeking Society", American Economic Review, 69 (3), pp 291-303. 
Magee, S. P., Brock, W., and Young, L., (1989), Black Hole Tariffs and Endogenous Policy Theory, Cambridge and New York: Cambridge University Press.

Maggi, G., and Rodriguez-Clare, A., 1998, "The Value of Trade Agreements in the Presence of Political Pressures", Journal of Political Economy, 106(3), pp 574-601.

Mayer, W., 1981, "Theoretical Considerations on Negotiated Tariff Adjustments," Oxford Economic Papers, 33, 135-43.

Mayer, W., 1994a, "The Political Economy of Tariff Agreements", Schriften des Vereins fur Socialpolitik, 148, 423-37.

Mayer, W., 1984b, "Endogenous Tariff Formation," American Economic Review.

McLaren, J., 1997, "Size, Sunk Costs, and Judge Bowker's Objection to Free Trade," American-Economic-Review, 87(3), 400-420.

McLaren, J., 1999, "A Theory of Insidious Regionalism," Working Paper, Columbia University.

Mitra, D., 1999, "Endogenous Lobby Formation and Endogenous Protection: A Long Run Model of Trade Policy Determination", American Economic Review.

Mitra, D., Thomakos, D. and Ulubasoglu, M., 2002, " 'Protection for Sale' In A Developing Country: Democracy vs. Dictatorship,", The Review of Economics and Statistics.

Olson, M., 1965, The Logic of Collective Action, Harvard University Press, Cambridge, MA.

Peltzman, S. (1976), "Toward's More General Theory of Regulation," Journal of Law and Economics 19 .

Rodrik, D. (1995), "What Does the Political Economy Literature on Trade Policy (Not) Tell us that we Ought to Know?," Handbook of International Economics, Vol. 3, North-Holland.

Staiger, R., (1995),"International Rules and Institutions for Trade Policy," Handbook of International Economics, Vol. 3, North-Holland.

Stigler, G. (1971), "The Theory of Economic Regulation," Bell Journal of Economic Management and Science, 2. 


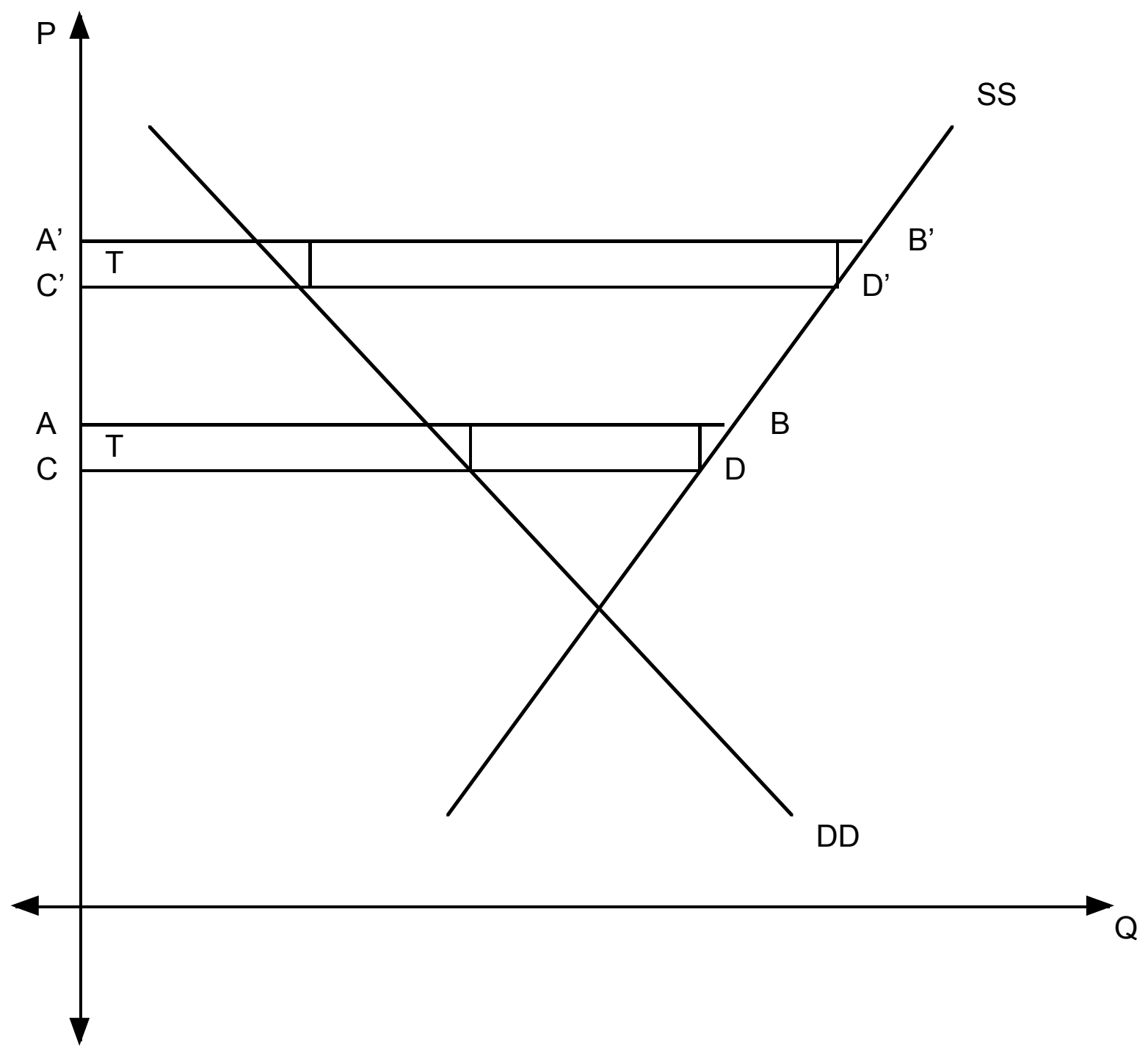

Figure I: Domestic Demand and Supply Curves for the Exportable Good 

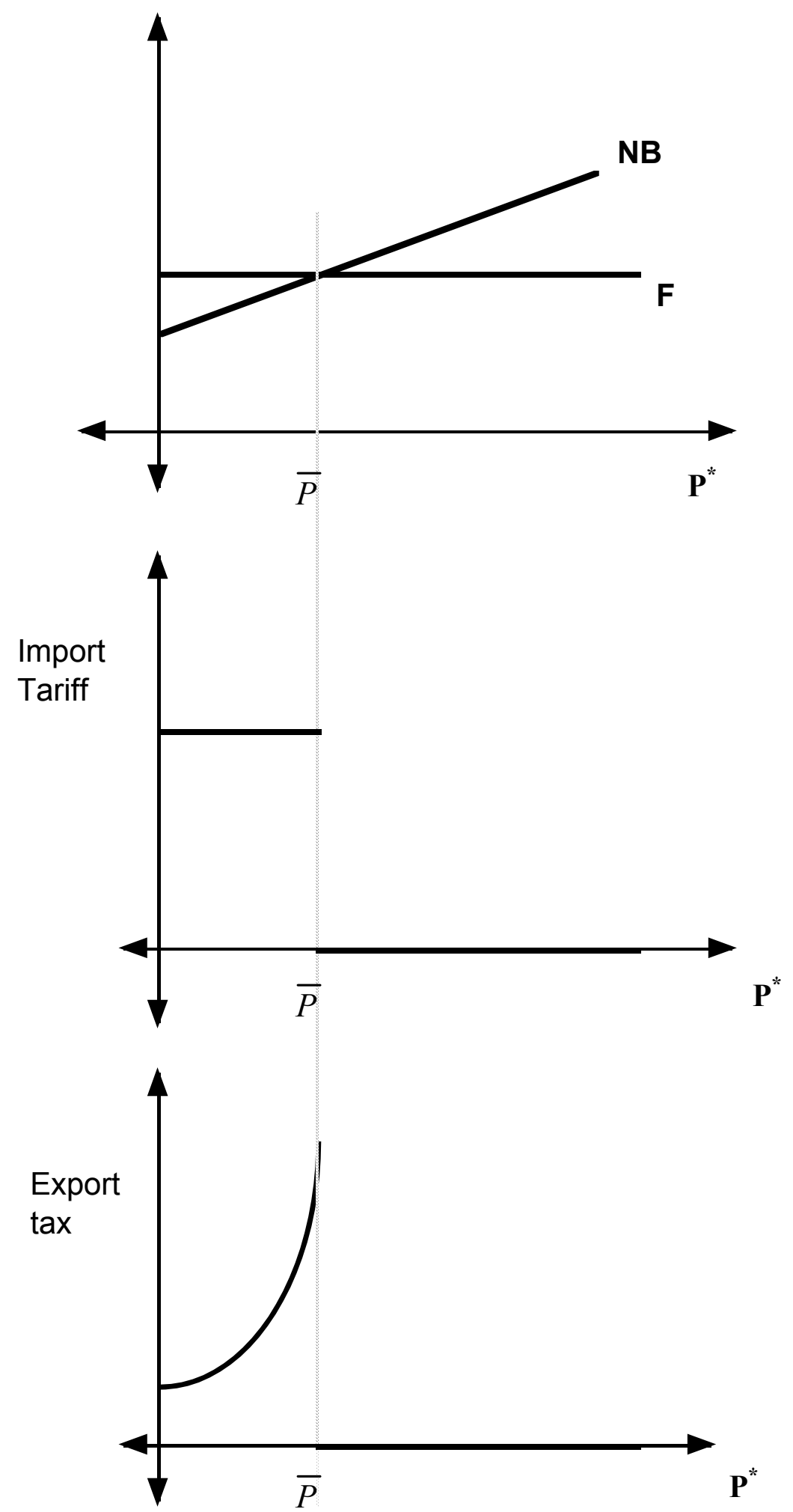

Figure II: Net Benefits from Lobby Formation and Trade Taxes vs $\mathrm{P}^{*}$ 


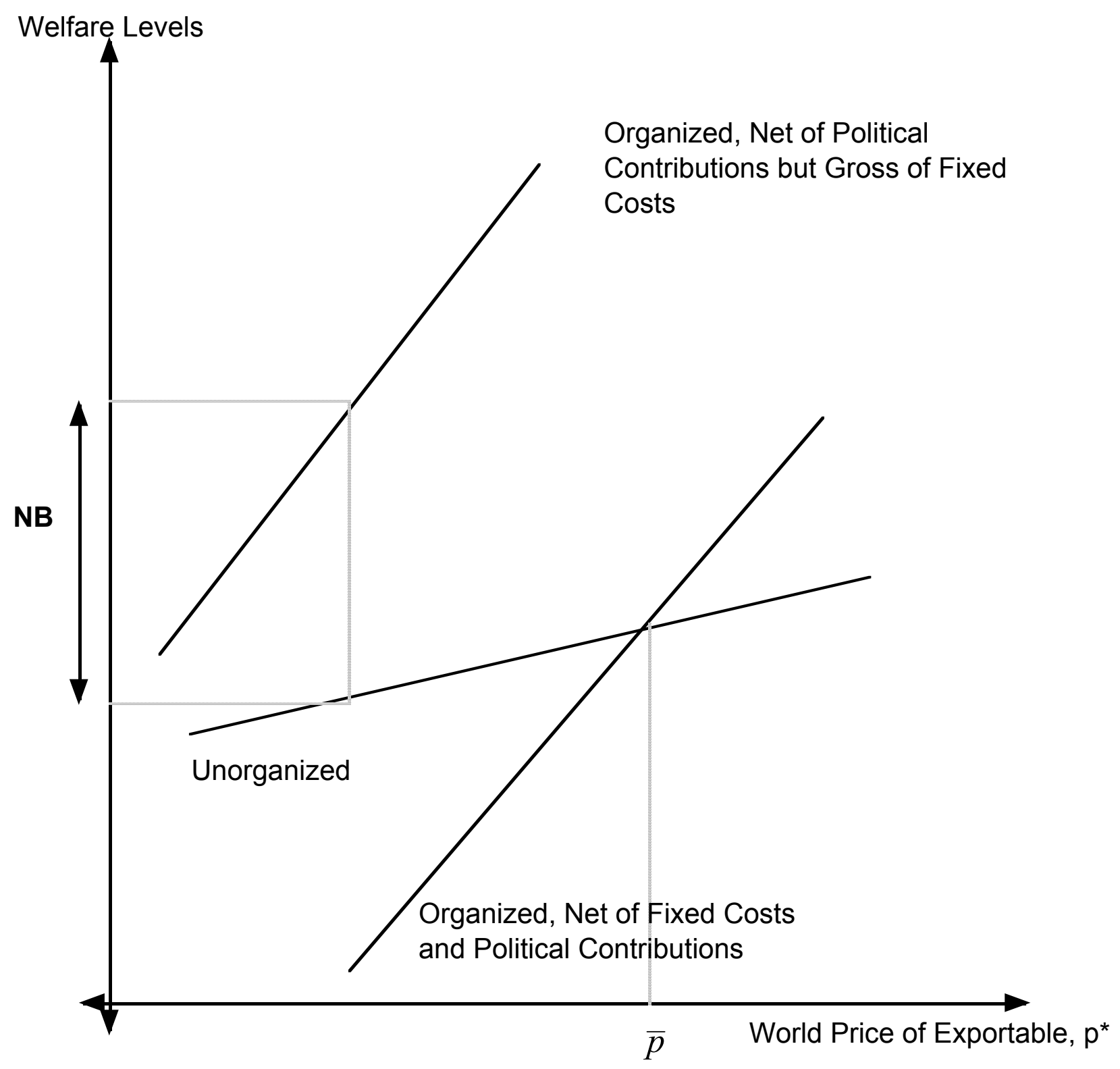

Figure III 

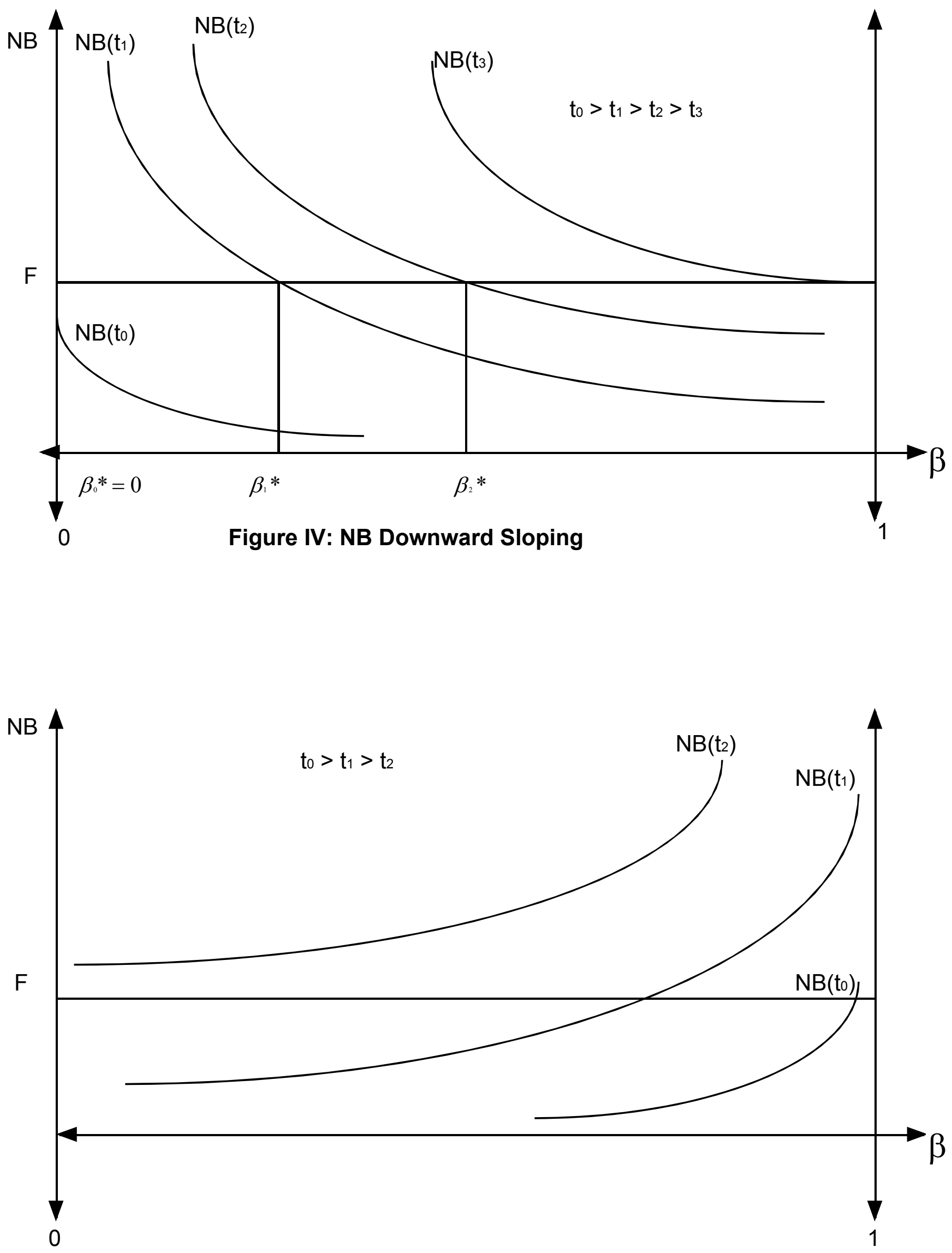

Figure V: NB Upward Sloping 

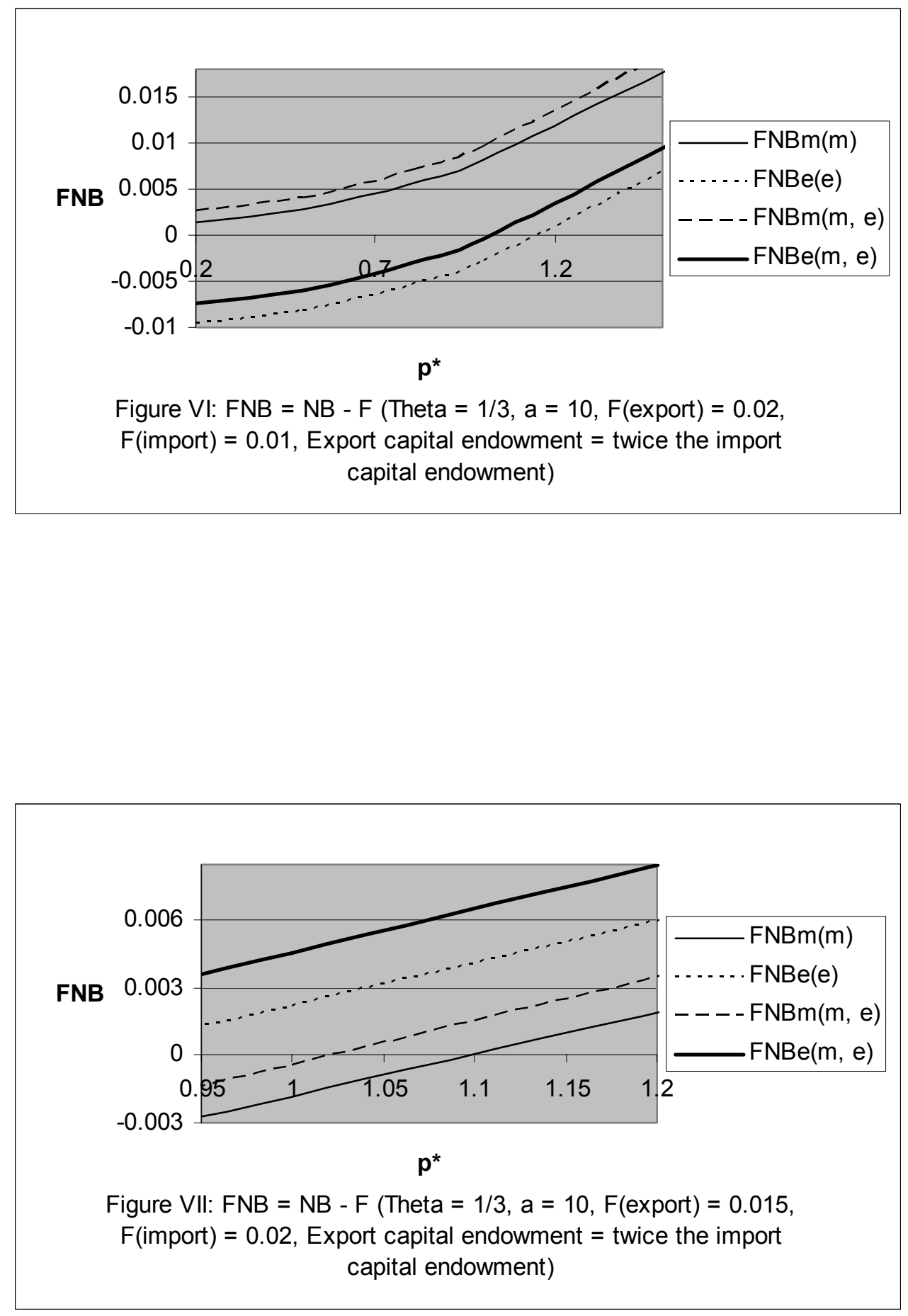


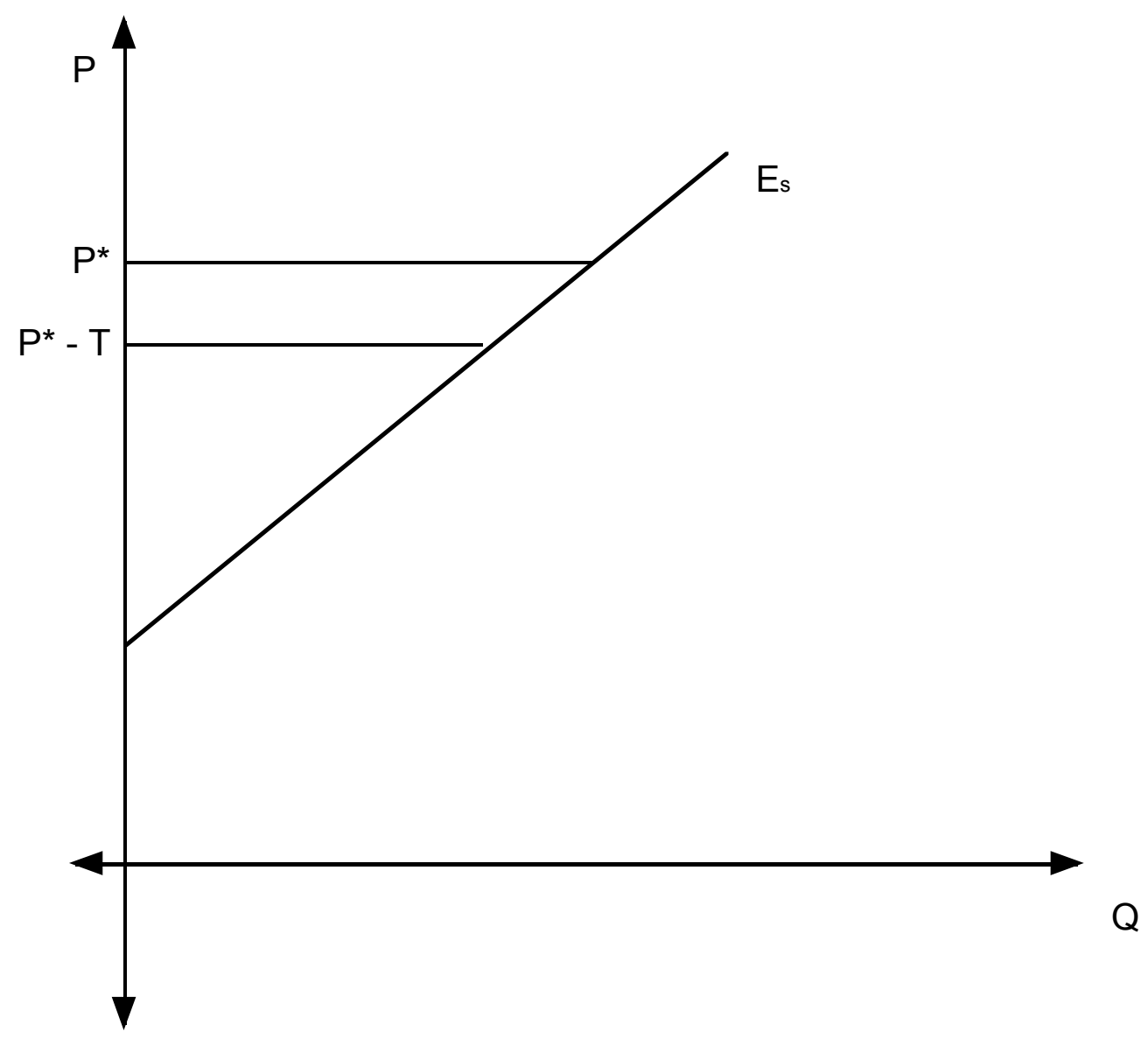

Figure VIII: Export Supply Curve 